PRIMO PLANT

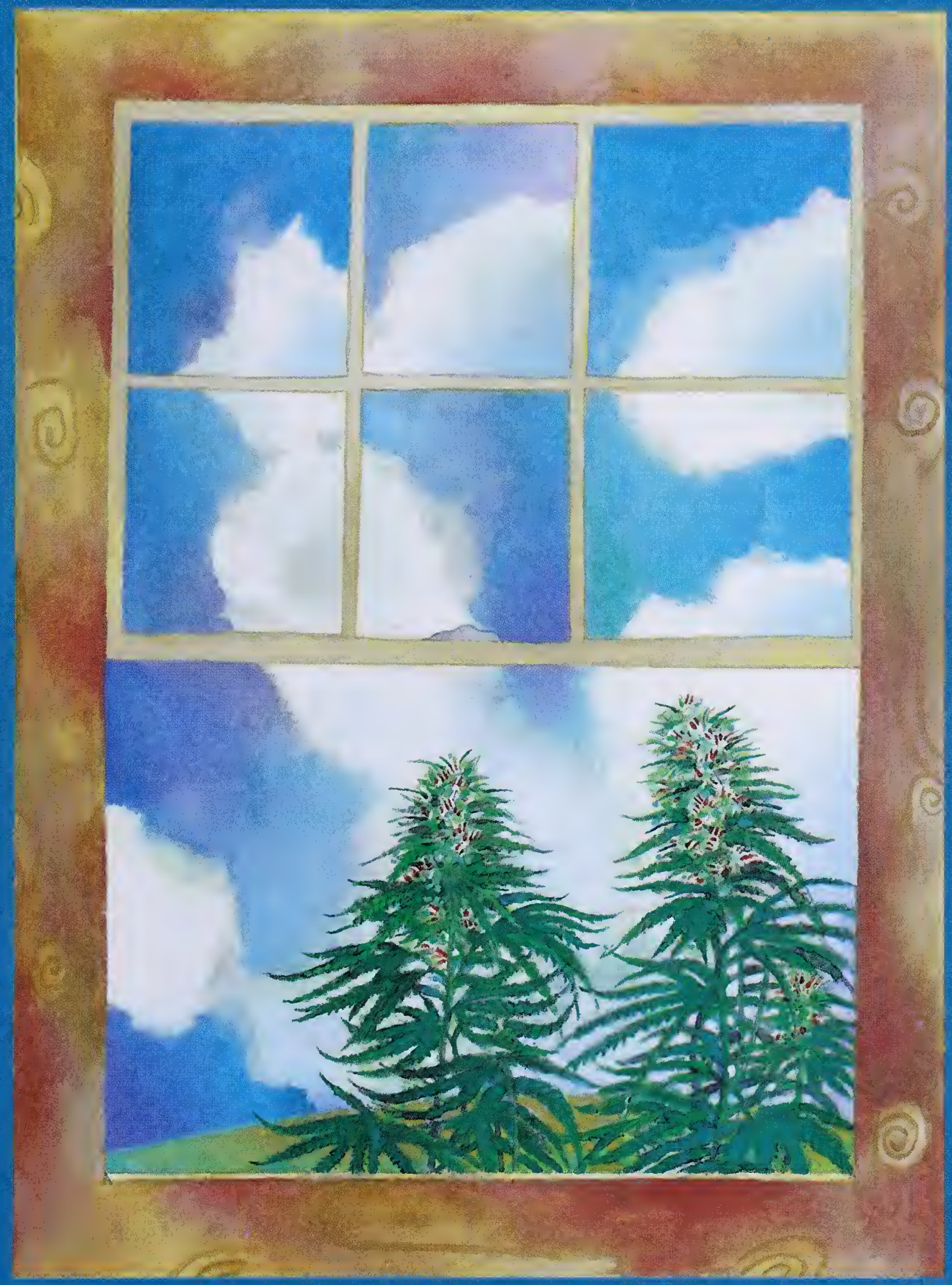

GROWING MariJUANa OUtDOORS

Mountain Girl 
Digitized by the Internet Archive in 2017

https://archive.org/details/primoplantgrowin00moun 


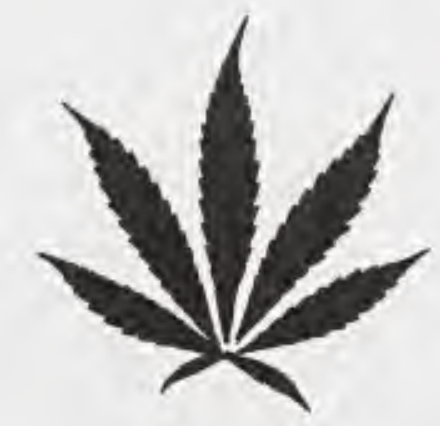

The Primo Plant 



\title{
Primo Plant
}

\section{Growing Marijuana Outdoors}

\author{
by Mountain Girl
}

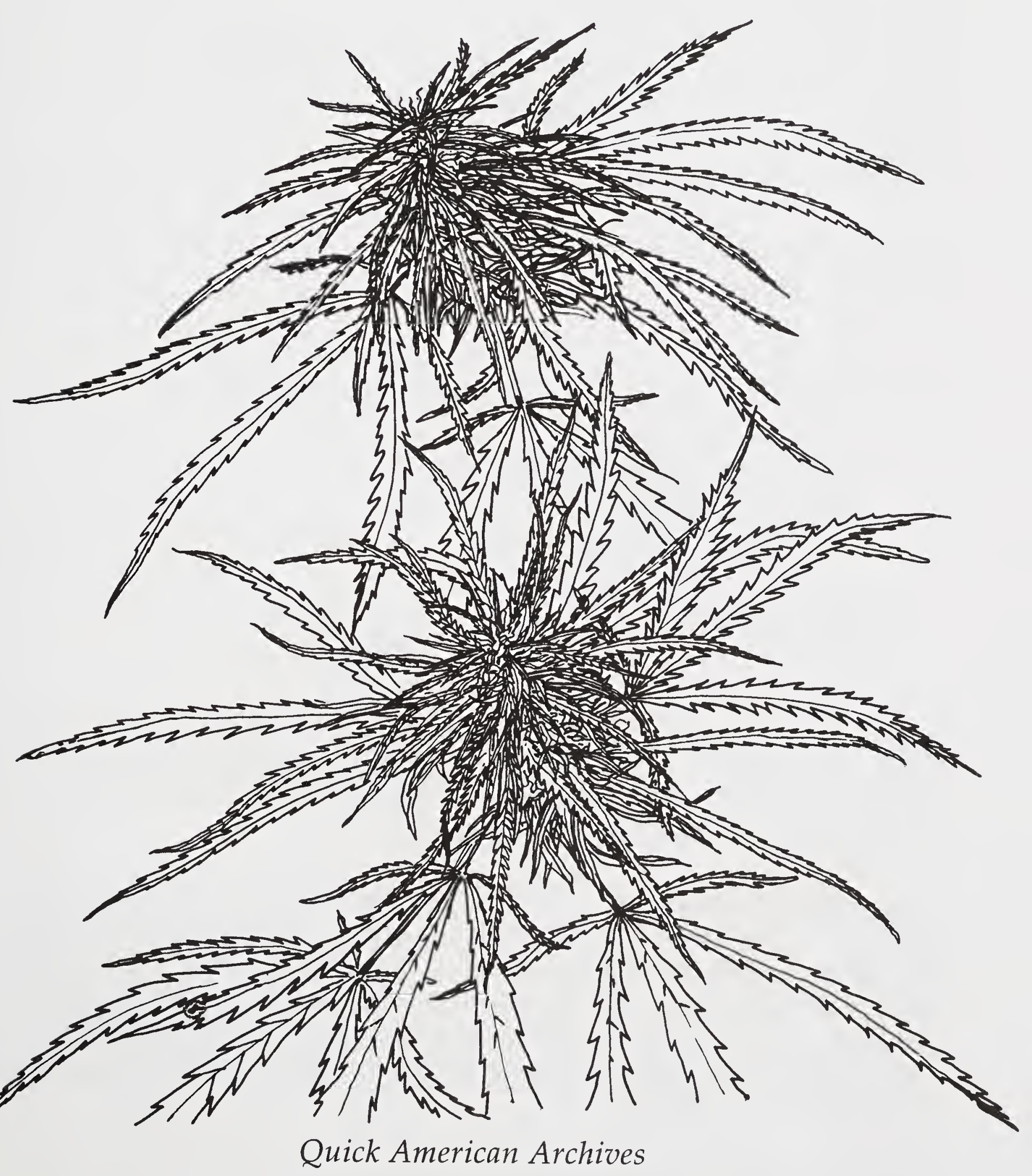


Published by Quick American Archives

Oakland, California

Copyright () 1998 Mountain Girl

Project Manager: Andrew McBeth

Editorial Assistant: Stephanie Rose

Cover Drawing and Design: Stefan Gutermuth wgdoublegee

Back Cover Photo (C) Barge, Cannabis Canada

Illustrations: George Brown

Typeset at Alphabet Express

\section{Publisher's Cataloging-in-Publication}

(Provided by Quality Books, Inc.)

Mountain Girl.

Primo plant : growing marijuana outdoors / Mountain Girl. - 1st ed. p. $\mathrm{cm}$

Includes bibliographical references.

ISBN: 0-932551-27-0
1. Cannabis.
2. Marijuana.
I. Title.

SB295.C35M68 1998

QBI98-227

The material presented in this book is presented as information which should be available to the public. The Publisher does not advocate breaking the law. However, we urge readers to support N.O.R.M.L. in its efforts to secure passage of fair marijuana legislation.

All rights reserved. No part of this book may be reproduced in any form without permission in writing from the publisher, except by a reviewer, who may quote brief passages or reproduce illustrations in a review where appropriate credit is given; nor may any part of this book be reproduced, stored in a retrieval system, or transmitted in any form or by any means-electronic, photocopying, recording, or other-without specific written permission from the publisher.

Printed in the U.S.A. by Publishers Express Press 


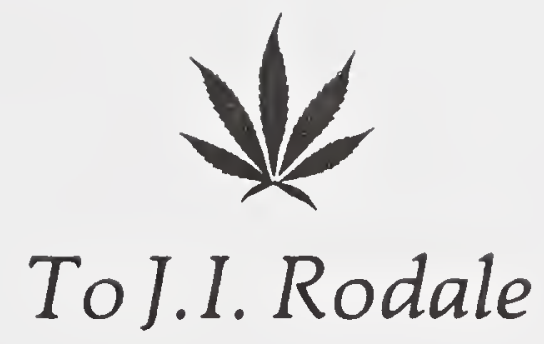




\section{Contents}

Introduction

\section{Part : Before Planting}

Climate

Seeds-You Get What You Plant

Types of Seeds

Storing Seeds

Where To Plant

When To Plant

Composting-The New Alchemy 22

To Begin Composting

Getting The Soil Into Condition $\quad 26$

\section{Part II : Planting}

Spacing Out

Planting

Lazy Bum Method

Meticulous Method

Keeping Track

Planting in Containers

Soil Mix For Containers

Greenhouse Culture

Problems

Indoor Growing

\section{Part III : Growing}

Germination

Transplanting

Seedlings into Peat Pots

"Hardening" Indoor Plants

Moving Larger Plants

Sensible Feeding 


\section{Part IV: Pruning \& Plant Care}

Pruning

Pinching

Cutting

Other Techniques

Rooting The Cuttings

60

61

\section{Part V : Flowering}

First Flowers

Sex Discrimination

64

To Seed Or Not To Seed

How To Grow All Female Plants

The Hermaphrodite

72

74

How to Prevent Runaway Hermaphrodism 76

Part VI : Harvest

Watching The Sun

Frost

Harvest Time-The Big Payoff

Chop Chop

82

Storage

84

\section{Appendices}

How To Know When Your Plants Need Help 86 Pests \& Diseases

\section{Pests}

Babies Fall Flat

Experimentation

Barney's Tequila Verde

94

Marijuana Butter

95

Selected Bibliography

96

Planting Notes \& Log 


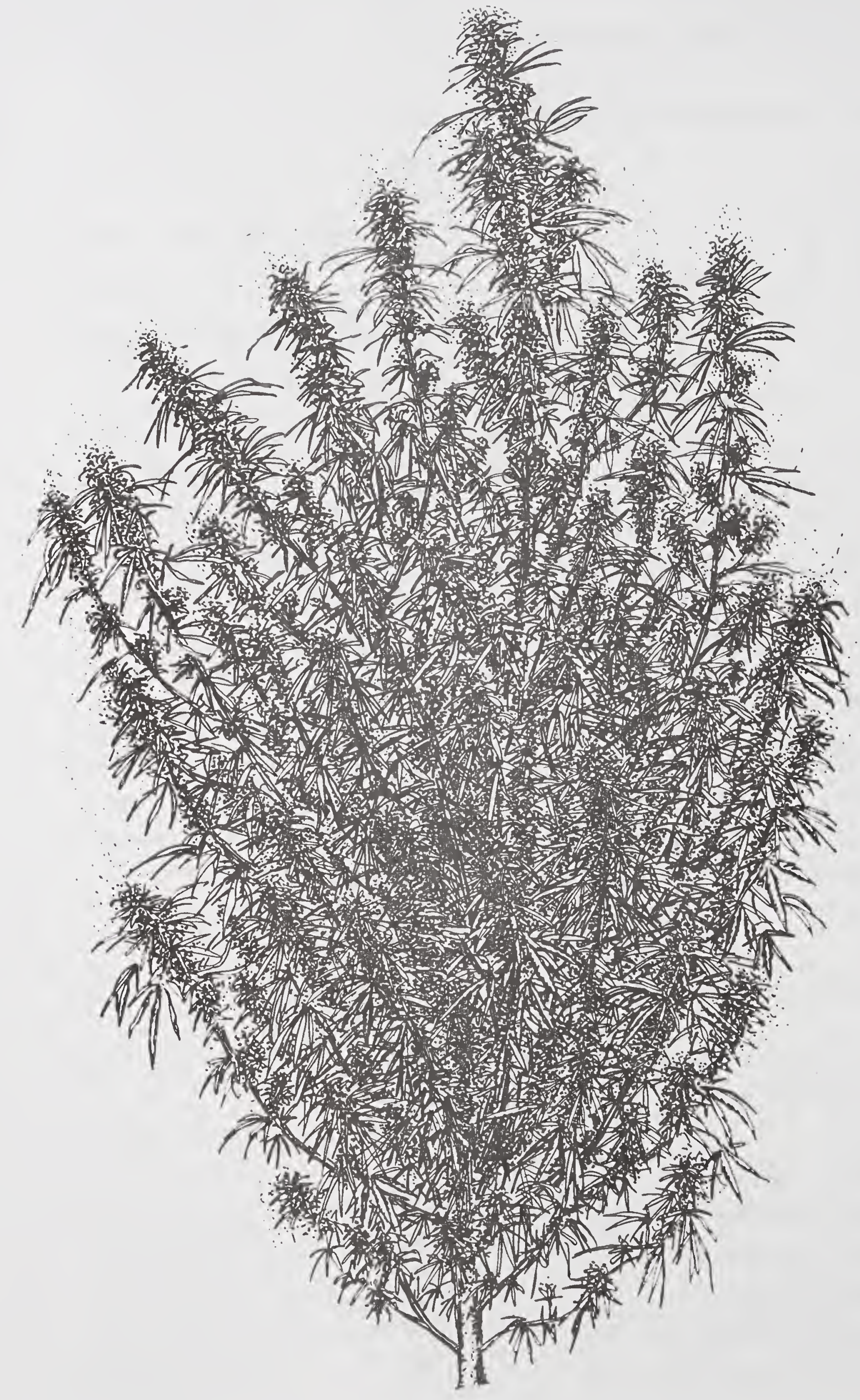




\section{Introduction}

$\longrightarrow$ HE PURPOSE OF THIS BOOK is to inform the public about growing marijuana, in all its diversity, to full perfection in America's different climate regions.

Oddly, much published information on pot growing is misleading \& incomplete. The truth is they really didn't know how. Growing marijuana is a natural act. Since the 1930's, Americans have been denied the right to grow this useful, beneficent friend.

Marijuana is an ancient plant, cultivated for centuries all over the world for rope \& papermaking, for its oil, resin, \& seeds. The Pre-Columbian cultures in North America certainly grew it, \& time-honored techniques of cultivation have survived in India, Southeast Asia, \& the Near East.

Old-time farmers used manure, compost, bird shit, etc. That was what was available, \& it is still the best.

Homegrown grass has had a bad name that clung for years. Only recently has domestic marijuana begun to excel \& rank with the best of the exotic imports.

Palates accustomed to Colombian and Hawaiian have discovered homegrown sinsemilla, \& are finding that there is something more that happens when you grow your own, really good, homegrown grass - a great, satis- 
fying feeling of the joyous power of great highs \& limitless highs to come.

Five or six big, healthy, female plants will supply a heavy smoker for a year with pure, organically-grown, harmoniously attuned grass. A grower with a good attitude-caring for the plants, protecting them, promising them a future for their seeds-will develop a sensitive relationship with his plants, learning from them \& getting high with them.

To grow topnotch grass successfully, one has to know certain key details. There are two methods I will outline; one of them calling for a long growing season with early planting \& production of females which are then transplanted to an outdoor site. A single healthy hunza female plant can produce a pound of seedless, top-quality weed with proper preparation \& love \& understanding care.

The other method, planting an unsexed garden \& letting it flower normally, results in equally good grass \& is probably easier for a beginner. In either method, knowledge is the key to success.

The legal status of growing is changing all across the country. In California, cops do not hassle growers of the backyard-personal-consumption variety unless they receive a complaint or they can see it from their cars. Some states are much cooler now that penalties are light, but in any bust you lose the plants. Landlords and realty agents are dangerous - have a good story ready. Other smokers are the real problem. They have a nose for it, \& word gets around. 


\section{Part I}

\section{Before Planting}

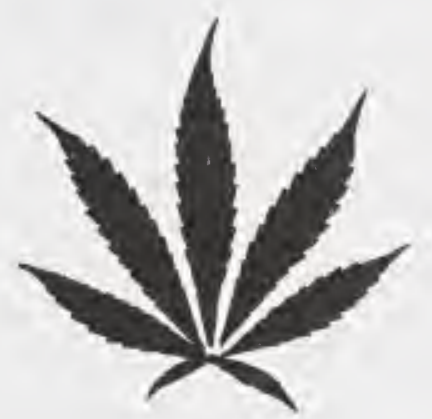




\section{Climate}

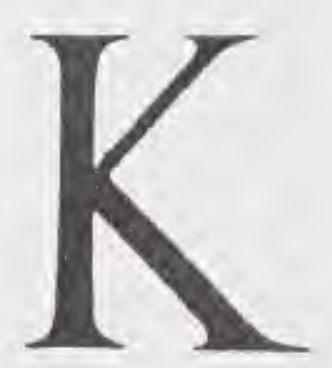

NOW \& UNDERSTAND your local climate. Within a small geographic region, for example, slight differences in altitude can produce microclimates unfit for growing grass. The best climates in the United States are found at low altitudes in California, Oregon, southern Arizona, southern New Mexico, Texas, the Gulf Coast States, \& warm parts of Georgia \& the Carolinas. These areas share a mild, snow-free winter.

The critical months in growing big marijuana plants outdoors are late September \& October. Is October in your area as warm \& sweet as it is in California, or cold \& bitter like Michigan? If you are located in high mountains with Alaskan winters \& short summers, indoor or portable gardens are the only answer. Fast greenhouse construction around threatened plants will hold off frost, especially if you are aware of passive solar energy techniques (like putting double windows in your greenhouse). Plants in large but portable containers, such as half wine barrels on dollies can be taken inside at night \& at other times when cold threatens. (See pages $20 \& 80$.) Unfortunately, late spring frosts can wipe out a young planting with one chilly night, so be cautious about setting out plants too early in frost-prone areas. The northern Midwest, eastern Oregon 
\& Washington, Idaho, Utah, Colorado, Montana, Wyoming, Nebraska, the Dakotas, Wisconsin, \& Michigan have frost until mid-May or the first of June;

New England is notorious for late spring frosts, making it necessary to start the plants indoors.

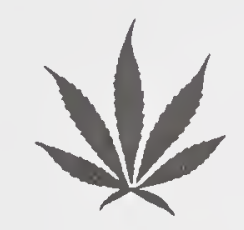




\section{Seeds}

\section{You Get What You Plant}

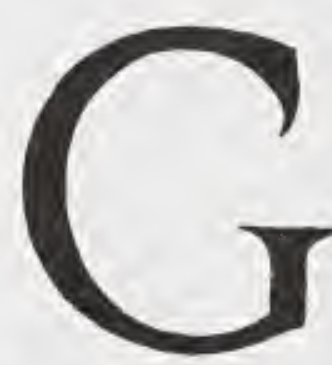

ET THE Right Seeds. Personal tastes vary, \& seeds differ according to genetic origin. The seeds you want are from the best of the stronghigh weed available. Choose "happy" pot \& avoid planting the "headache" or "sorethroat" type. Seeds from strong strains will produce strong grass in the home garden. Seeds from homegrown of past years will have improved over the original imported strain only if the grower has deliberately selected his very best plants each year to use for seed. Fifthgeneration domestic grass may have degenerated considerably if no selective process was used. In some countries where families have been cultivating marijuana for generations, breeding carefully for their ideal plant, the seeds are jealously guarded.

It's easy to beg a few seeds from someone with highquality marijuana. Remember, highs will differ depending on the genetics of the seed. Climate \& growth conditions determine only how well the plant grows, not its chemistry.

\section{Types of Seeds}

There are many distinct types of marijuana, ranging from plants with enormous broad leaves \& long, fat 
flower tops to equatorial types with tiny, skinny fernlike leaves \& numerous small flowers. These characteristics are all inherited. The different types are as varied as the many cultures they come from. Each tiny area, or even each grower, has developed a type of flower, distinct \& true to itself.

The large-leaved varieties grow better in temperate parts of North America: possibly they originated in mountainous regions. The northern Mexican types mature quickly in colder North America.

Humid, sub-tropical, \& hot areas, such as Florida, Louisiana, Gulf Coast \& Texas, southern California, southern Arizona, \& southern New Mexico, produce excellent results from the tropical types, such as Colombian, Vietnam, Thai, \& Congolese. Other types will also flourish magnificently. Cold-winter areas should stick to largeleaved varieties, unless you are growing indoors or in a hothouse.

Mild climate areas, such as coastal California \& Oregon \& cool desert areas, are suitable for growing largeleaved varieties, but the slim-leaved tropicals will perform only moderately well unless the weather is perfect.

Some tropical strains respond less quickly to changes in the light. Mexican plants flower quickly \& strongly in autumn's solar decline, whereas equatorial Colombian lingers on \& on in the garden on its own time schedule.

Panama: Strong, fast-growing plants. Very large flowers, strong harsh taste, medium-large leaves, dense heavy high.

Colombian: An extremely variable weirdo from the equator. Often weak, delicate plants, with small leaves, many, many tiny flowers that mature late. Sometimes large, loose flowers with slightly larger leaves. Excellent high if matured properly, but difficult in some areas. Best in a greenhouse anywhere that is cold in November. The 
equatorial zone has no seasons, \& the plants barely respond to shortening days.

Maui or Kona: "Royalty" in domestic circles-carefully selected bloodlines have resulted in a superior plant. Extra big leaves, large flowers, very aromatic, fastgrowing. Maui Wowie is an early bloomer. Highly recommended.

Thailand, Vietnam: Usually slow to germinate, often scrawny or stunted. Pale, fernlike leaves, small flowers. Tremendous high, but hard to grow outside, except in the hottest parts of the United States. Worth the extra hassle.

Jamaican: Good basic stock. Strong growing plants, strong taste, large leaves, big flowers.

Nepalese: Large beautiful flowers, curving delicate leaves, fine taste, smallish elegant plants, strong high.

Mexican: A tremendous variety of types, with variations in color from red \& purple to yellow \& tastes from oranges to chocolate. It's all Mexican. Medium-size plants with a good yield. Strong stems, flowers \& leaves that vary widely. Michoacan can have spiky, upward-pointing leaves, while the huge Oaxacan leaves bend gracefully back. Recommended, but select carefully.

\section{Storing Seeds}

Keep different seeds in separate labeled containers. Take care that they don't get overheated; keep them dry \& cool. Room temperature is fine. Seeds will also survive storage in the freezer.

When you consider seeds for planting, test them for life. Crack a shiny dark one \& examine what's inside: there should be a white substance with green skin, the taste sweet \& oily, not sour. Pick out a few shiny fat ones \& place $1 / 2$ inch deep in a cup of dirt \& soak with warm water. Leave the cup indoors at room temperature and 


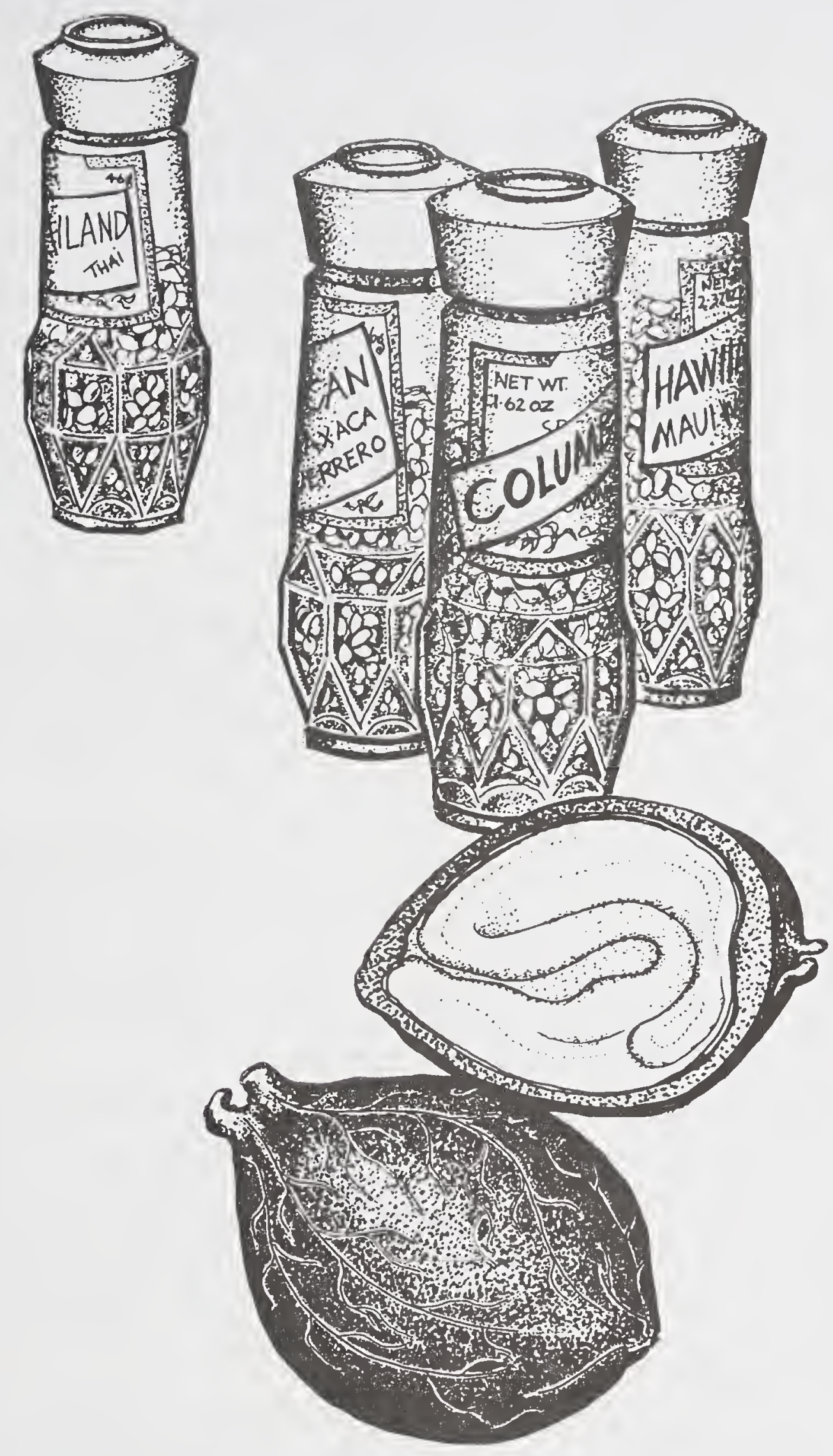

seedlings should appear in six days. If the seeds have not sprouted, shake out the dirt \& look for seeds that may have rooted.

Some seeds just don't grow, maybe from too much heat in transport. Try again with different seeds.

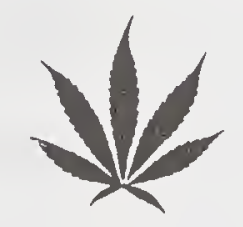




\section{Where To Plant}

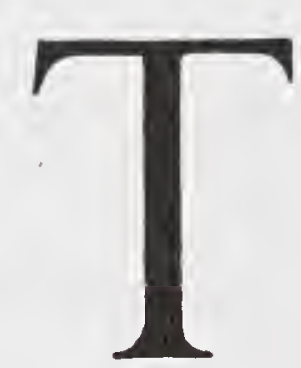

HE PROBLEM FOR MOST PEOPLE is the planting place. Those who have no garden \& no shrubbery or woodlands close by should move to a better place or try indoor culture.

The ideal planting site is a hidden clearing that receives full sun all day \& has rich, rock-free soil, a good water supply, \& wind protection. In more northern areas, the site must be elevated to receive maximum sunlight in autumn \& to drain off cold air.

A southern exposure is the warmest \& lightest; a spot suitable for nude sunbathing is ideal. Whatever you do, don't block the sunlight to the plants (use a compass to locate due south). The growing site must get real strong sunshine most of the day. Protection from the wind may be needed in some areas.

If you do it in the woods, try to avoid pines \& evergreens. These produce an acidic soil that can seriously stunt growth. Avoid swampy or salty spots. The loose, rich soil along streams is ideal for woodland growing. Try to plant in south-facing meadows, or in areas of lowgrowing brush, or along the tops of hills \& ridges to maximize the light-especially important for northern growers in areas where cool weather may prevail in autumn. If you have to plant under the trees, do it on a 
south-facing slope for the most light. The plants will never get very large or strong, but will bloom \& mature to give potent grass.

Marijuana rooted in a cold, wet soil will grow and mature more slowly, with a dark green color, producing less vigorous vegetation and blossoms.

Plants that are grown in shady areas will grow large blossoms of a deep green color. Hot sunshine will grow smaller, denser blossoms with a more golden tint, sometimes pale yellow or pale frosty greens.

Beware of hunted areas, heavy deer populations, bunny rabbits, \& ground squirrels. Small mesh chicken wire, painted black or dark green, keeps out marauders invisibly. A foot-tall cylinder of chicken wire pinched together at the top and staked down will protect the young plant, which most rabbits, deer, horses \& cows find irresistible. Older, tougher plants don't get nibbled as much.

Cheapo plastic greenhouses work fine for concealment, as do simultaneous plantings of giant sunflowers, sweet corn, or pole beans. Grass is decorative-looking \& disappears in a formal garden behind shrubs or hedges.

Be sure to test the $\mathrm{pH}$ of the soil carefully. Inexpensive $\mathrm{pH}$ paper is available at garden stores. $\mathrm{A} \mathrm{pH}$ of 7 to 8 (neutral to somewhat alkaline) is ideal. Be sure to test both the topsoil \& the subsoil about 12 inches under. Soil test kits are available, but not a necessary expense.

Water must be made available in drought areas. Even a tiny dribble will be sufficient for most small efforts.

Before planting in dry areas, try installing a drip or sub irrigation system (widely available through gardening magazines). These come with automatic timers \& use far less water than conventional systems.

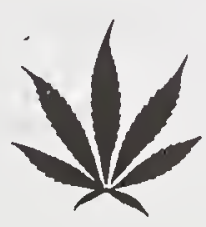




\section{When to Plant}

\section{Climate and Temperature}

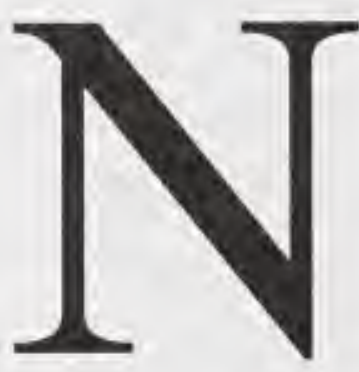

o matter when marijuana is planted between

May 1 and Aug 1, it will flower at approximately the same time. This means that it can be planted outdoors over a long period.

Obviously, the earlier plants are started, the bigger they will get. Age at maturity has no effect on potency; it is rather the degree of maturity and the heredity of the seed that determines potency and type of high.

Marijuana should be planted outdoors at about the same time as corn and tomatoes, after the soil has warmed up a bit and supports rapid germination and growth.

The later the planting, the more care that has to be taken during the first few days. As the Spring warms up, it requires more care to keep the soil moist. Plants transferred from shady or indoor gardens need to be shaded from the burning sun as they adjust to their new location.

In milder climates where the soil stays warm, plants grown outdoors anytime between September 21 and Jan. 1 immediately begin to flower and are harvestable in eight to ten weeks. In places where the winter days are warm with cold nights, the plants can be kept in pots and brought into a dark spot in the house each evening, protecting them from the cold and forcing them to flower at the same time. 


\section{Location and Latitude}

The further away from the equator you are the longer the summer day and shorter the dark period. June 22, the first day of summer is the longest day of the year. On Sept. 22, the first day of Autumn, the day is equally divided between light and dark throughout the world. After that the dark period gets longer more quickly at higher latitudes.

This is important to know because marijuana flowers depending upon amounts of uninterrupted light and darkness. For example when a plant gets five or six consecutive nights with a minimum amount of uninterrupted darkness it turns its growth from vegetative; leaves and stems, to reproductive; flowers and seeds.

If all varieties of marijuana were triggered by the same number of hours of darkness, say 10 hours, they would still flower at vastly different times depending on where they were located. Plants in the south, closer to the equator would flower in mid summer because of long periods of uninterrupted darkness (nearly 12 hours) while plants in the far north would have little time to flower before frost set in because of the short dark periods each day; and the fast advent of autumn.

Most varieties of Afghani or Indica plants, which are the most commonly used for indoor Sinsemilla, are more likely to be triggered into flowering earlier than Mexicans and other southern types. Many Indica, when grown in the southern half of the U.S. flower early, producing smaller buds. They are good for the northern half of the country because the shorter nights of mid-summer do not have enough dark time to trigger flowering.

Sativas and Sativa hybrids perform well in the southern part of the country. These plants will resist flowering too early so they will yield large buds. In northern areas they will begin flowering late and not be ready to harvest before the frost. 


\section{Composting- The New Alchemy}

$\longrightarrow$ HERE ARE REALLY TWO ATTITUDES you can take to gardening. One is the never-get-dirty-buy-itall-in-plastic-bags-sterile-weed-free approach. The other is the self-reliant-make-do-withwhatever-get-down-dirty-organic-composting method.

Composting is the creation of billions of decay bacteria which change organic stuff into a brown crumbly blend called "humus." Compost has an almost magical effect upon plants. The very finest marijuana plants are grown on soil where something is rotting, on heavily composted or manured soil, or on compost heaps-or even where one once was.

Chemical fertilizers injure plants if sloppily applied, \& they also affect the taste.

Making compost is accelerating natural soil-making. Soil is made of weathered rocks \& decayed plant materials, plus billions of microscopic bacteria \& fungi. There are approximately 20 million bacteria living in 1 gram of topsoil (provided that it hasn't been poisoned by chemical farming). These microorganisms appear \& flourish on a steady diet of decaying vegetable material \& animal bodies, including their own, adding humus \& vital life 
energy to the soil. Compost techniques create an Eden for this microlife in the soil, encouraging earthworms \& strong plant growth.

The beauty of making compost is that wastes which are usually a problem to dispose of may easily be converted to plant food by means of a simple, natural process. To make your own compost, collect some of these things:

Old leaves, rakings, or weeds

Fresh lawn clippings ("green dynamite")

Carrot pulp

Fish scraps

Dried flowers

Bone meal

Manure-horse, goat, rabbit, sheep, chicken, or cow Old hay or rotten straw

Well-rinsed seaweed

Wood ashes, white \& dry

Chopped-up kitchen garbage (no meat or fat)

Avoid using: Brush; chipped bark; wood, stemmy or stickery stuff; broken glass; stringy long grasses; dog \& cat manure; pine needles; sawdust. These take too long to break down.

A good basic formula is 100 pounds wet manure, 100 pounds leaves or old hay, 100 pounds fresh grass clippings.

If a shredder is used composting is speeded up because everything is broken up into "bacteria hash" \& a much wider variety of plant material can be used. Compost made only from shredded material is ready for use in fourteen days \& needs no layering. 


\section{To Begin Composting}

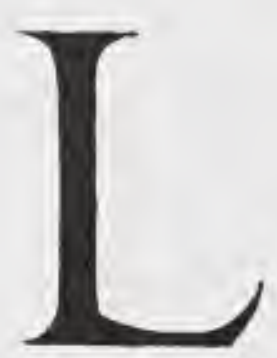

OCATE NEAR YOUR GARDEN a 3-foot-high circle of chicken wire or similar enclosure; it's important that as much air as possible be allowed to circulate.

To begin the pile, put down a bottom layer of weeds or brushy vegetation. This will keep the rest of the pile slightly off the ground for airiness. Then put down a 3-inch-thick layer of whatever you have the most of. . . strawy manure, rotten hay, leaves ... sprinkle it with a thin layer of chopped, organic garbage, then a thin layer of topsoil. Now add a solid 2 or 3 inches of fresh, wet manure or grass clippings, which contain the activating element nitrogen. Continue with another layer of bulky, airy stuff like leaves, fresh weeds or strawy manure. Airiness is very important. If your materials are dry, sprinkle each layer thoroughly with water as you build. The heap should be very moist but not sopping wet.

Continue to build, with no layer exceeding 3 inches. Use thin sprinklings of powdered natural fertilizers such as bone meal, rock phosphate, wood ash, blood meal, fish meal, etc., throughout the heap.

Finish the heap with a thin layer of fine dirt \& water the whole thing with a sprinkler for a minute. Cover it with burlap bags or straw for insulation. Within two days 
the heap should be hot in the middle. If not, add more manure or grass clippings \& douse the cold pile with liquid fish fertilizer.

The pile will become hot \& steamy. Success. Decomposition has set in. Rapid decay releases heat that kills seeds \& toxic organisms, \& the temperature can go higher than 150 degrees Fahrenheit. The pile will begin to sink to half its original size. Stick a garden fork in it from time to time \& fluff it up a bit \& once in a while thoroughly churn it up; the extra air speeds the process. Sprinkle it with water whenever it begins to get dry, but protect it from heavy rains with plastic. Turn the pile as it begins to cool off, \& it is ready to use when everything has turned brown \& crumbly in a month or two.

Compost is used in several ways. The fine-textured stuff can be sifted out with $1 / 2$ inch mesh hardware cloth \& used in planting mixtures. The rougher stuff can be returned to another heap or used as a top dressing to keep the soil open and moist underneath the plants, or it can be used to make compost tea, which will be described later on (See page 50).

For complete information on organic composting look for The Complete Book of Composting or The Encyclopedia of Organic Gardening (See bibliography).

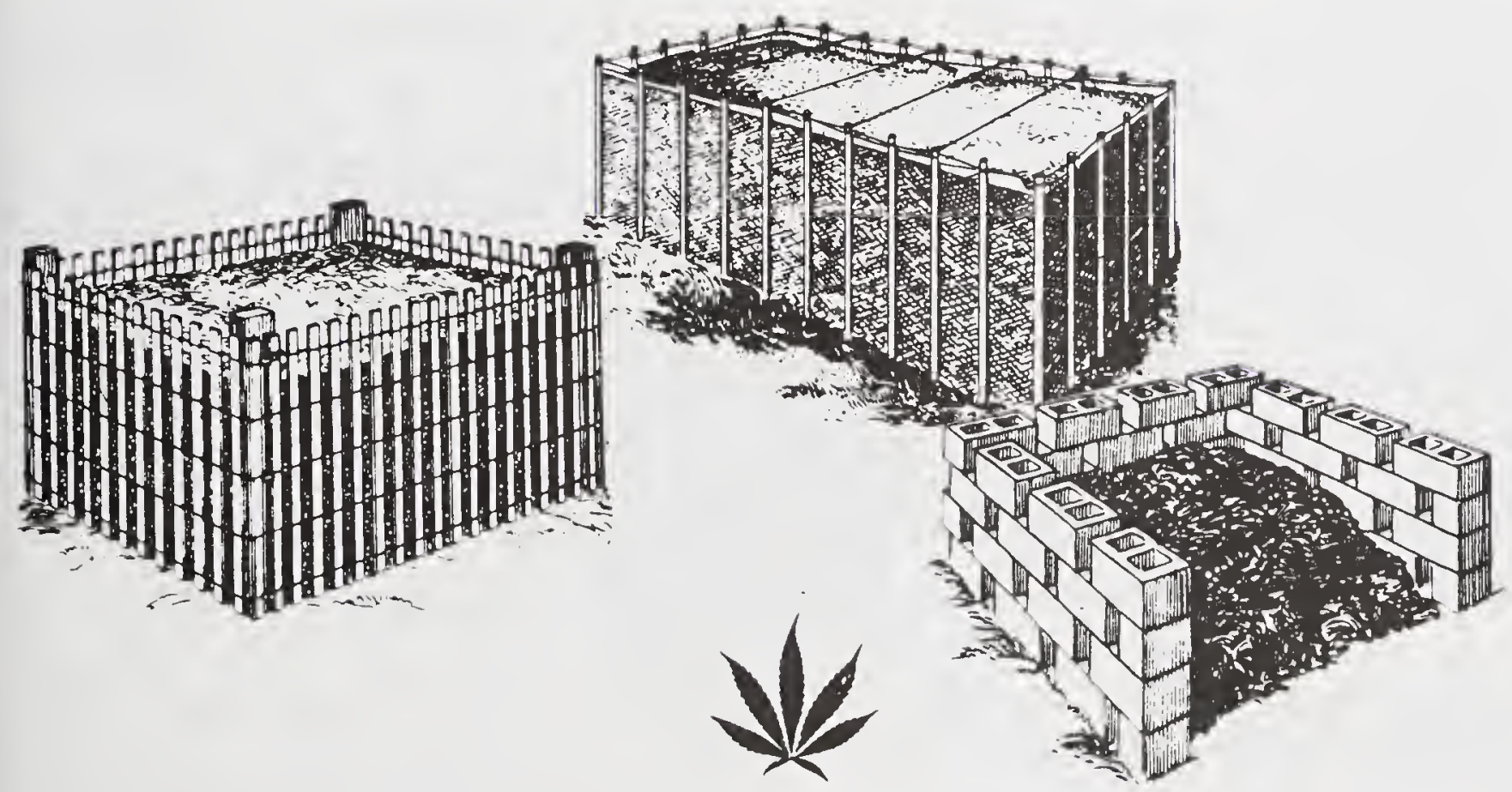




\section{Getting The Soil Into Condition}

DEALly, THE PLANTING SoIL should be rich, deeply cultivated, fine-textured, warm, loamy or sandy, with a slightly alkaline $\mathrm{pH} \&$ a calcium-rich subsoil.

For large plantings, rototill deeply \& repeatedly in spring, plowing under any available amount of manure, compost, green grass, weeds, rotten hay, dead leaves, \& poultry manure at the rate of 40 cubic yards per acre. If the soil tested somewhat acidic ( $\mathrm{pH}$ under 7 ) scatter dry woodashes \& agricultural limestone to alkalize the planting area. If the site doesn't drain well \& tends to stay soggy \& cold, make raised planting beds by digging out paths 1 foot wide \& 6 inches deep, laying the soil in long mounds 2-3 feet across. Be sure not to compact the soil by walking on the raised beds.

If you contemplate a smaller garden, obtain a garden fork for digging, for each plant dig a hole* at least 18 inches across \& 1 foot deep. Set the soil to one side. Fill the hole with a good shovelful of recent manure, a similar shovelful of good-quality compost, a large handful of bone meal, \& about $1 / 2$ shovelful of dried chicken shit. You can also add rotten kitchen garbage, eggshells, dead fish, dried 
kelp, sewage sludge, earthworms, cottonseed meal, crushed granite, old manure, a dead snake, or whatever you might have that will decay quickly. Marijuana plants really respond to rotting materials in the ground. Add limestone, about 1 pound per plant; 2 pounds if the soil is acidic.

If the soil is very dense \& heavy, add a shovelful of sand \& plenty of extra compost. Do not substitute peat moss or commercial "organic compost" or "soil conditioner," as these are very acidic logging wastes.

Next, mix the holes well, crumbling any big lumps, then putting back enough of the original topsoil to raise the level a few inches above the surrounding ground. If the ground remains hard \& uncultivated, the fragile plant roots cannot spread out enough to grow more than a dwarf plant.

Soil types differ wildly across the United States. In the eastern half \& in the wet northwest, acid soil is the rule,

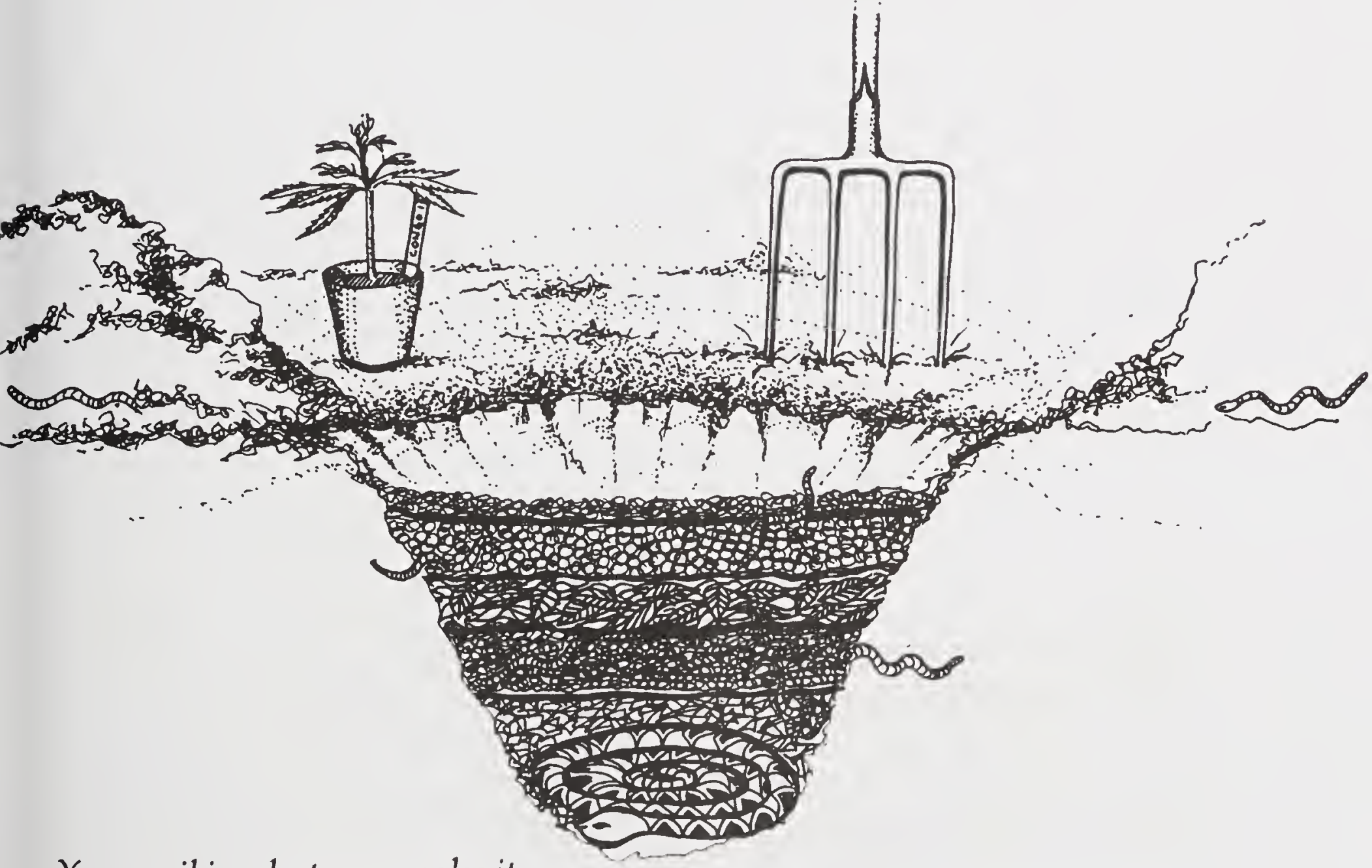

Your soil is what you make it 
correctable with lime \& compost \& special attention to drainage. Arid desert areas are alkaline \& need organic matter worked in. Rich adobe soils, common clay of the West, give sensational gardens when compost is added. The midwestern prairies are fertile \& acidic in wet areas, semifertile \& slightly alkaline in dry areas.

The conditions around the roots are responsible for the feeding \& support of a seed that will grow to the size of a ten year old Christmas tree in four short months, so get plenty of food into the ground before planting. The roots are mostly delicate, hair-like \& not very extensive even in very large plants, \& they grow best in well-cultivated soil. 


\section{Part II}

Planting

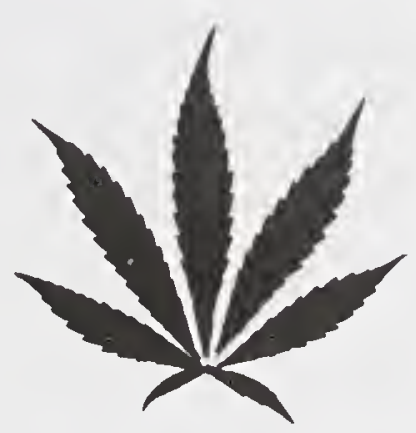




\section{Spacing Out}

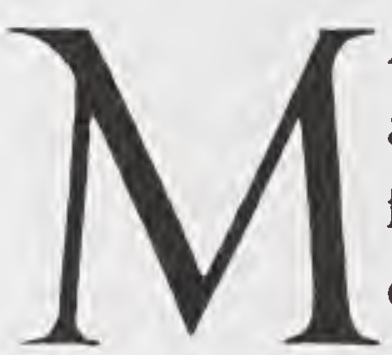

ATURING FEMALE PLANTS should stand 5 or 6 feet apart. Top-to-toe all day sunshine is essential for perfect plants; no plant should shade another. Given enough space for sun, each plant will produce to its maximum in perfect health. Very wide spacing causes prodigious side branches to form \& the plants grow wide \& full.

Overcrowding produces shade, \& shade produces more male plants. A crowded garden will grow very tall \& lanky, giving very small yields per plant.

In a wild garden where both male \& female plants are growing, a closer spacing of 2 to 3 feet should be used. The males are removed later, leaving extra light \& space for the females to mature slowly. In colder, damp conditions, it is essential that sunlight touches the ground between the plants to warm the soil.

Only in extremely hot dry areas is the shading unimportant. Moroccan farmers crowd their plants in a few inches apart, \& they grow acres of it. 


\section{Planting}

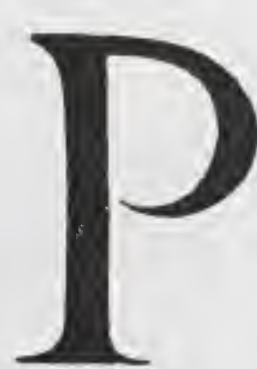

LANTING THE SEEDS directly outdoors produces very strong, healthy plants, if the soil is good. Prepare the soil thoroughly using raised beds or the prepared-hole technique. * Put three or four seeds around the center of each hole, about $1 / 2$ inch under the soil. Sprinkle the soil well; if it's dry, soak the area thoroughly. Wait six to ten days for the plants to come up. Water daily, lightly, unless the soil is already wet. Pinch off some of the babies if they are crowded. When they are six inches or so tall, cut off all but one sturdy child in each group. Save the seedlings with visible branches starting at each leaf joint. Cut off any that look twisted, spindly, or sick.

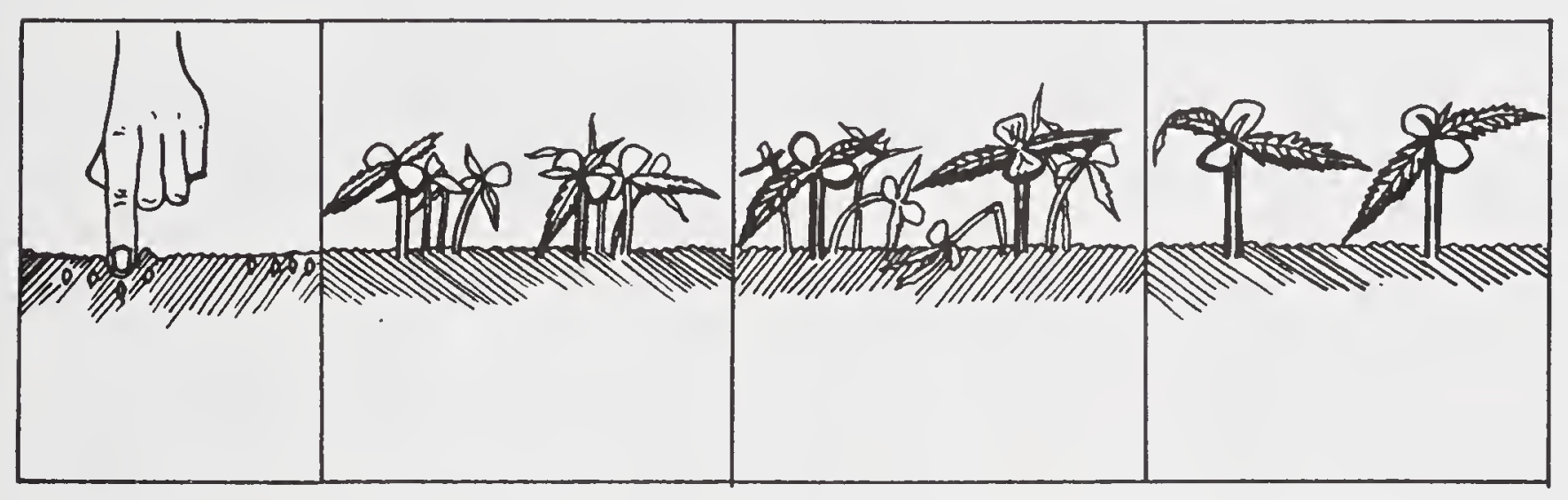

\section{Lazy Bum Method}

It's also possible just to throw some seeds down on good, well-dug garden soil, rake them in, sprinkle the

"See "Getting the Soil into Condition," page 26 
entire area well, \& stand back. Thinning is an absolute must: widely separate the strongest plants before they reach 8 inches.

Don't forget this stuff is a weed \& will grow under difficult conditions, depending on the soil \& sun, but the perfect plant requires loving attention.

\section{Meticulous Method}

I use \& recommend peat pots, available in most garden stores, a clever invention of a hollow pot made of pressed peat moss \& manure. The roots grow right through the pot, so transplanting is totally painless for the infant plant. Jiffy-7s are also good, but contain chemical fertilizer.

Fill the pots with a mixture of $2 / 3$ sand \& $1 / 3$ top soil or sifted compost, well mixed together. Don't pack it down, \& don't fertilize. Place the filled pots in a plastic or foil-lined box \& crowd them together so they won't tip over. Sprinkle thoroughly \& let them sit overnight. Then water them again before planting to make sure they are evenly moist.

Put one or two dark shiny seeds in each pot \& fill to the brim with more soil mix. The seeds should be about $1 / 2$ inch under the surface. Peat pots must never dry out after the seeds are planted.

Don't soak, sprout, or germinate the seeds before planting. This is a total waste of time \& a worthless hassle.

Keeping Track

It's difficult to resist planting several different kinds of pot, \& different is how they turn out. They all look alike at first, so number-label each pot, recording the number \& seed type in a special notebook. It's good to know what 


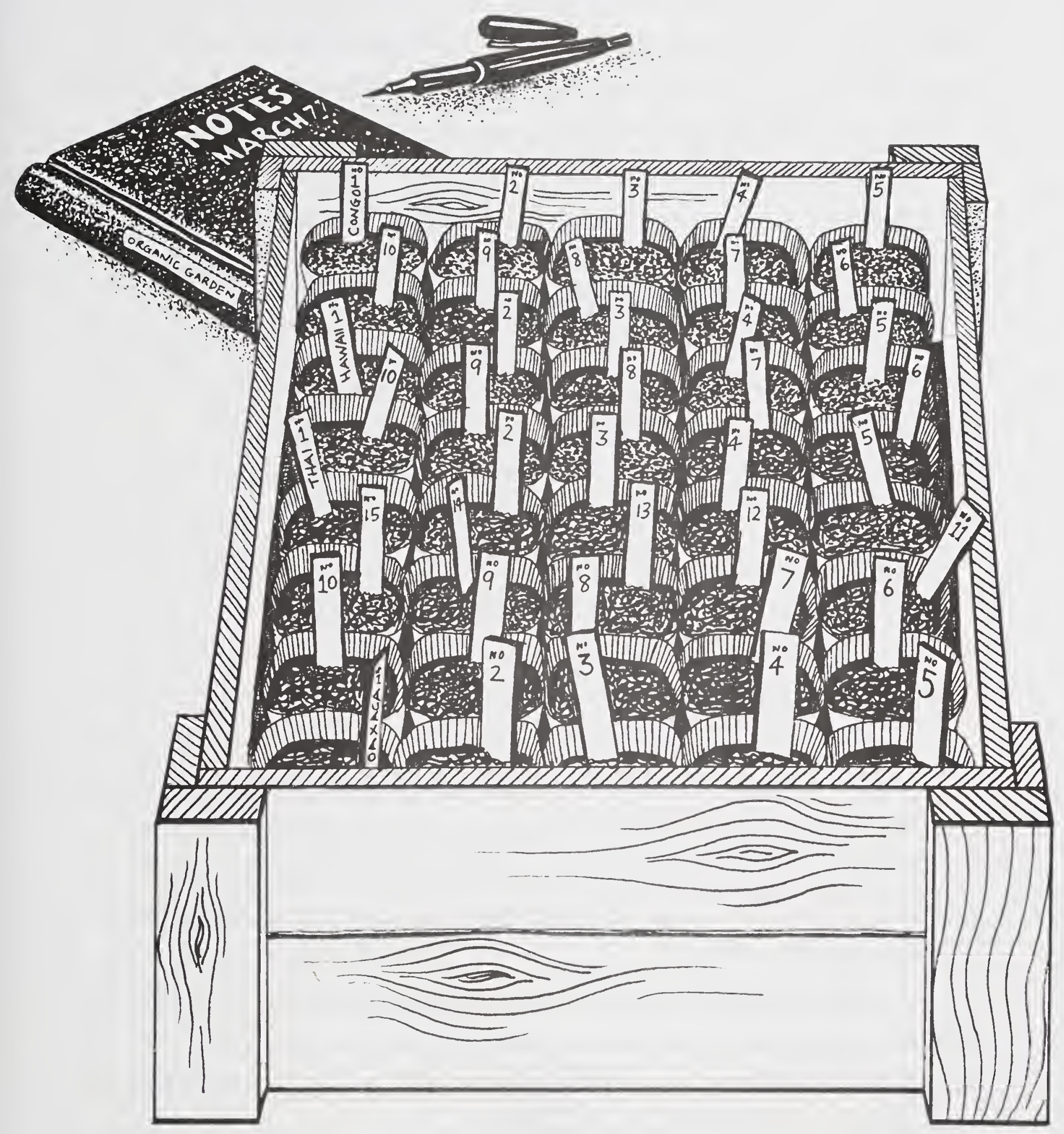

Planted \& Ready (For strong, healthy plants, keep peat pots evenly moist at all times.) 
you have. Don't use water-soluble ink. *

\section{Planting In Containers}

Practical containers to consider for portable gardens are half wine barrels, big plastic buckets with side handles, washtubs, even a plastic bag set in a fruit crate. Giant peat pots are also good. All planting containers need to be clean and free of detergents, oil, or bad chemicals. Be certain there is a small drainage hole in the bottom of each to prevent accidental drownings. For a large-size plant with a well-grown root system, use a large container at least 18 inches across \& 14 inches deep.

Whip up a special soil mix, one that will fully satisfy every requirement of a fast-growing, hungry infant. Careful, painstaking attention to this soil mix will insure successful growing, \& organic ingredients can be added in strong doses without injuring the plants. When planting in containers, use at least half sand. Sand is essential for perfect drainage, aeration, \& easy root penetration.

\section{Soil Mix for Containers:}

2 parts sand, 1 part good garden soil with earthworms in it, 1 part good compost or old decayed manure. Mix these well together. Test the soil for its $\mathrm{pH}$ value. If it is acidic, under 7 , step up the amount of lime \& ashes you feed the plant.

Half fill your planting containers with this mix \& then add a mixture of 1 cup bone meal, $1 / 2$ cup white wood ashes, $1 / 2$ cup lime, \& a little of any other organic natural fertilizer:

*Or use the special pages at the back of this book as your planting log. 
Sewage sludge

Dead fish in pieces

Kelp flakes

Blood meal

Hoof \& horn meal

Powdered rock fertilizers

Old eggshells

Dried chicken shit

Finish filling the containers with the original soil mix so that the heavily fertilized soil is at the bottom. This gives the roots a chance to select what they want. It is most essential to double check the $\mathrm{pH}$. Add another $1 / 2$ cup lime if it is even slightly acidic.

Thump the containers on the ground to settle the soil. It should remain soft \& light.

You can plant three or four seeds right away. Place them a couple of inches apart in the center \& cover them with $1 / 2$ inch of soil. Sprinkle the containers gently with pure water. This first watering must be thorough, soaking all the way down to the bottom to get things working before the roots reach it days later. Be sure water flows out the drain hole; the plants loathe standing in a bath.

Drive a long stake into the container near the edge. This will support the plant during hard times.

You will notice that the seedlings always point directly at the sun, following it through the sky. When moving plants in containers, try hard to realign them the same way each day. Perhaps it would be clever to mark one side of each pot \& always point it east. Constant turning of the plant must confuse it \& tire it out. 


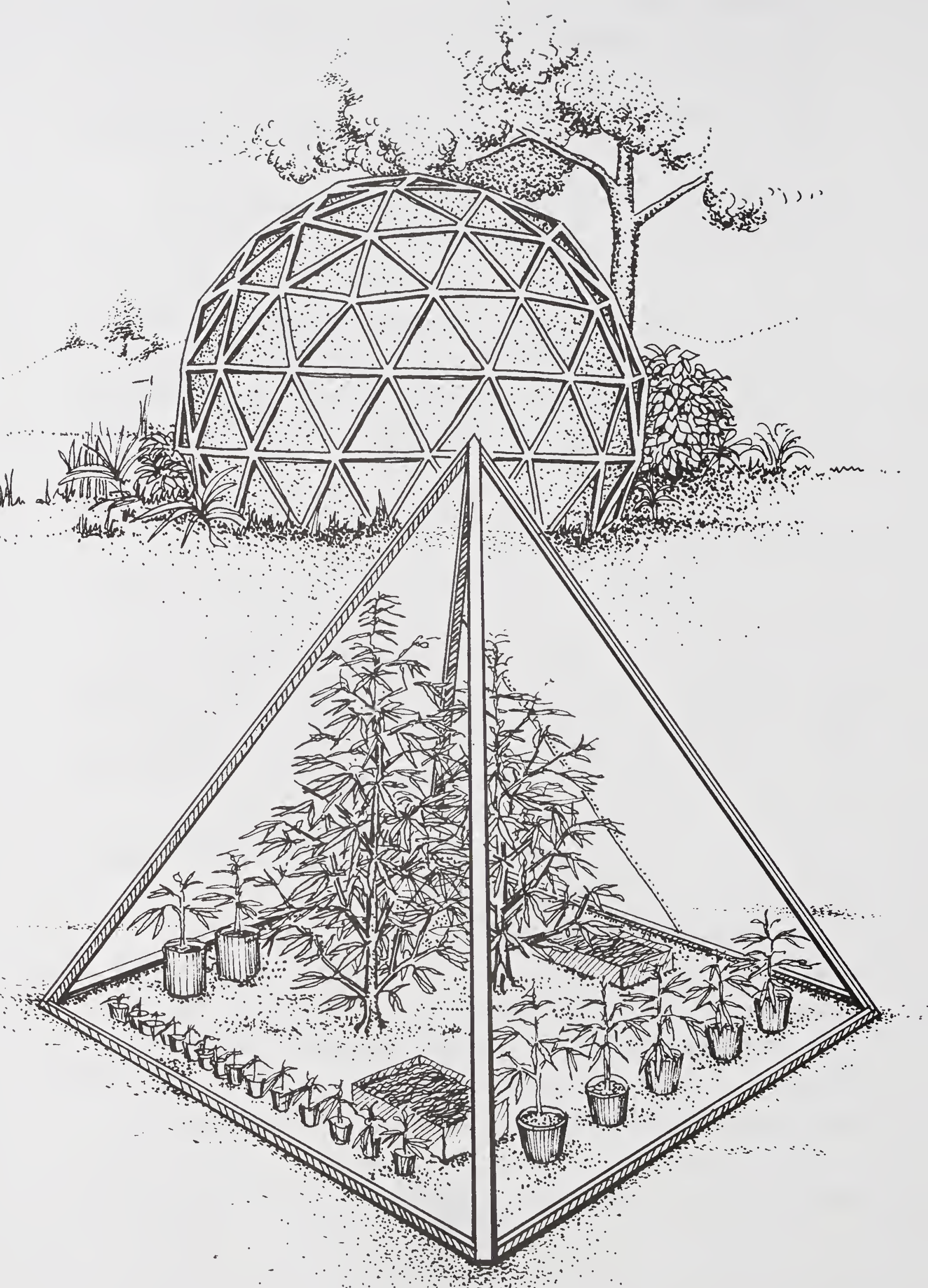




\section{Greenhouse Culture}

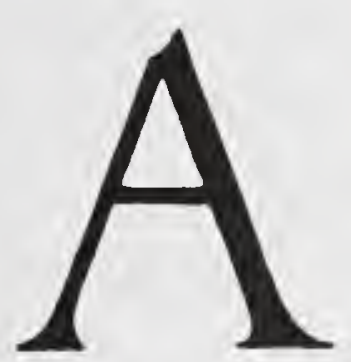

GREENHOUSE IS THE NATURAL SOLUTION for gardeners in heavy weather areas. It can provide backyard concealment, windbreak, \& frost protection, as well as prolong the growing season. It can also provide an outlet for architectural fantasy. However, greenhouses do have some disadvantages involving heat, pests, \& air flow. Nevertheless, in extremely cold, foggy, or windy areas they may be necessary for good growth.

Locate the greenhouse in the sunniest spot available. The cheapo roll plastic (PVC) \& scrap lumber greenhouse is fine if built strongly enough to withstand wind \& rain. It must also be tall enough - at least 8-10 feet, or the tops of the plants will hit the roof \& get twisted. In very cold areas, a double-walled greenhouse should be considered; it is simple to apply an inner skin after the weather turns icy.

Planting in the greenhouse is similar to planting outside. Care in soil preparation will pay off in healthy plants. Good spacing will probably yield to greed, but try to keep the plants at least 2 feet apart to stimulate some branching. They will do very well planted in the ground; rototill in as much organic \& natural fertilizers as you can. Excellent results may be had with careful culture in 5 gallon cans, half barrels, or other large containers. Avoid clay pots, as they overheat \& dry out rapidly, are breakable\& expensive. 
Obviously it is not going to rain inside the greenhouse, so watering must be done at least weekly, \& a semipermanent water system built in is a great help.

The yield from a greenhouse can be as high as 1 pound per 12 square feet.

\section{Greenhouse Problems}

Watch out for overheating. Keep a thermometer in a shady spot inside the greenhouse \& check it on hot, sunny days. More than 105 degrees is too hot; open it up more. A too tightly closed greenhouse can smother plants: with too much heat \& moisture in the air, toxic wastes can't evaporate off the surface of the leaves fast enough, \& poisons will build up that can seriously weaken the plant. So a steamy tropical environment is not necessary. Cannabis thrives at $75^{\circ} \mathrm{F}$. with dry air. A strong crossdraft of fresh air from outside is vital to good health.

Damp greenhouse conditions also produce live pests. If a mysterious gray mold appears, this is a definite indication that the air is too wet. Snails \& slugs should be removed to a distance or killed; they are an especial threat to seedlings. Spider mites are practically invisible bugs which produce a whitish mottling or stippling on the undersides of the leaves; lady bugs can be ordered through the mails to control spider mites \& aphids.

Greenhouse plants may grow too fast, suffering from a lack of wind. The stems grow long, floppy, \& weak. A gentle shaking each day helps strengthen them, as does an extra dose of potash - seaweed extract is fine. Also, the extra bit of shade from the overhead plastic will make plants lankier \& taller. Most of these problems can be remedied simply by removing the roof or constructing the greenhouse to be open during the day. The walls can remain to block prying eyes while the plants enjoy the natural advantages of free air \& light. 


\section{Indoor Growing}

T ndoor growing offers security. You must be content that the plants will not reach a great size or weight, so grow lots of them to make up the difference. Gro-Lux lights should be used in combination with regular incandescent bulbs, which give off some warmth, but they are no replacement for real sunlight. Plants grown exclusively in an artifical environment will never attain the size \& luxuriance of naturally-grown plants. Organic soil mixes \& compost teas will work well indoors, but do not produce the magical effects of outdoor growing.

There are several books on the market about indoor pot growing, but none take the organic approach.

Hydroponic or soil-less gardening can be done organically using blood \& bone meal liquid mixtures. This is a new field, ripe for experimentors.

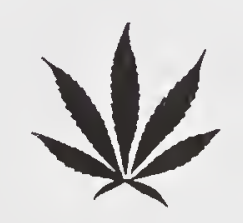




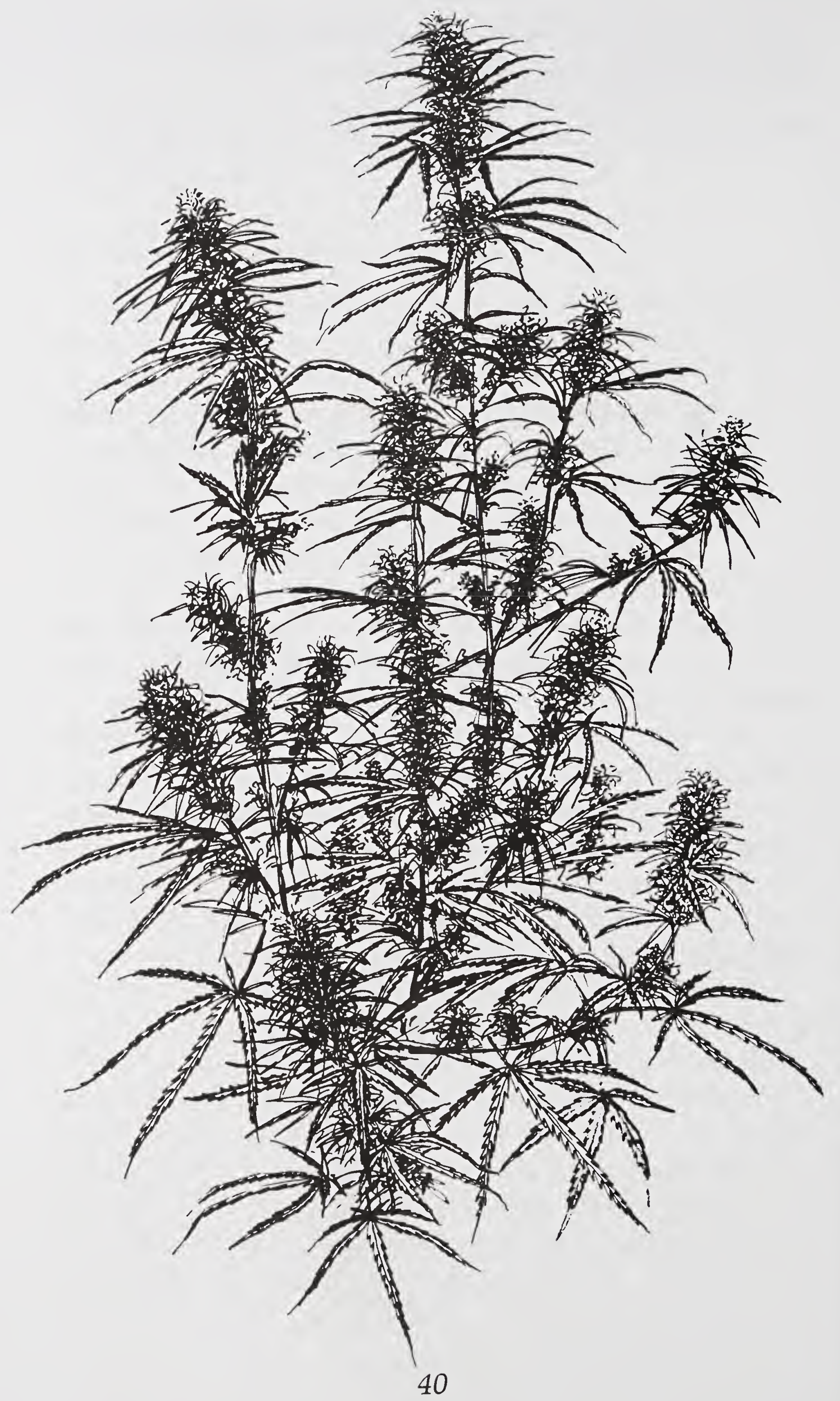




\section{Part III}

Growing

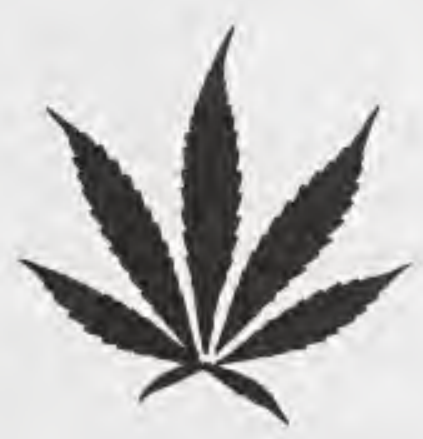




\section{Germination}

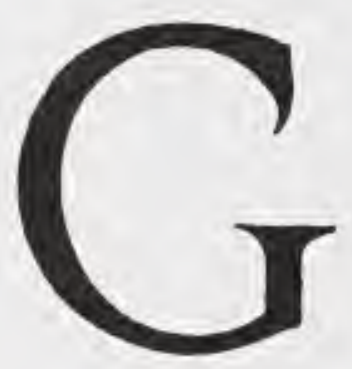

ERMINATION SHOULD TAKE PLACE in two to four days, with plants appearing after five to eight days. Seedlings need temperatures of 65 to $75^{\circ} \mathrm{F}$. Mist or sprinkle the pots once or twice daily to prevent drying, but make sure no loose water remains in the bottom of the box. Get the box into the sun as soon as the first plant appears. Put it in your sunniest window or outside during the day. Direct sunlight is essential for seedlings; without it they will stretch out long \& skinny \& never grow right.

Protect the seedlings from curious cats, snails, slugs, \& little kids. Lift a pot to check for roots: fuzzy white, coming through the bottom. Twelve to fifteen days after germination is an average wait. When the roots appear, transplant immediately into the prepared soil.

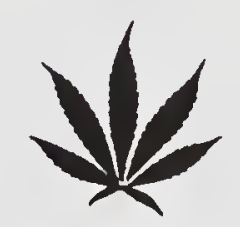




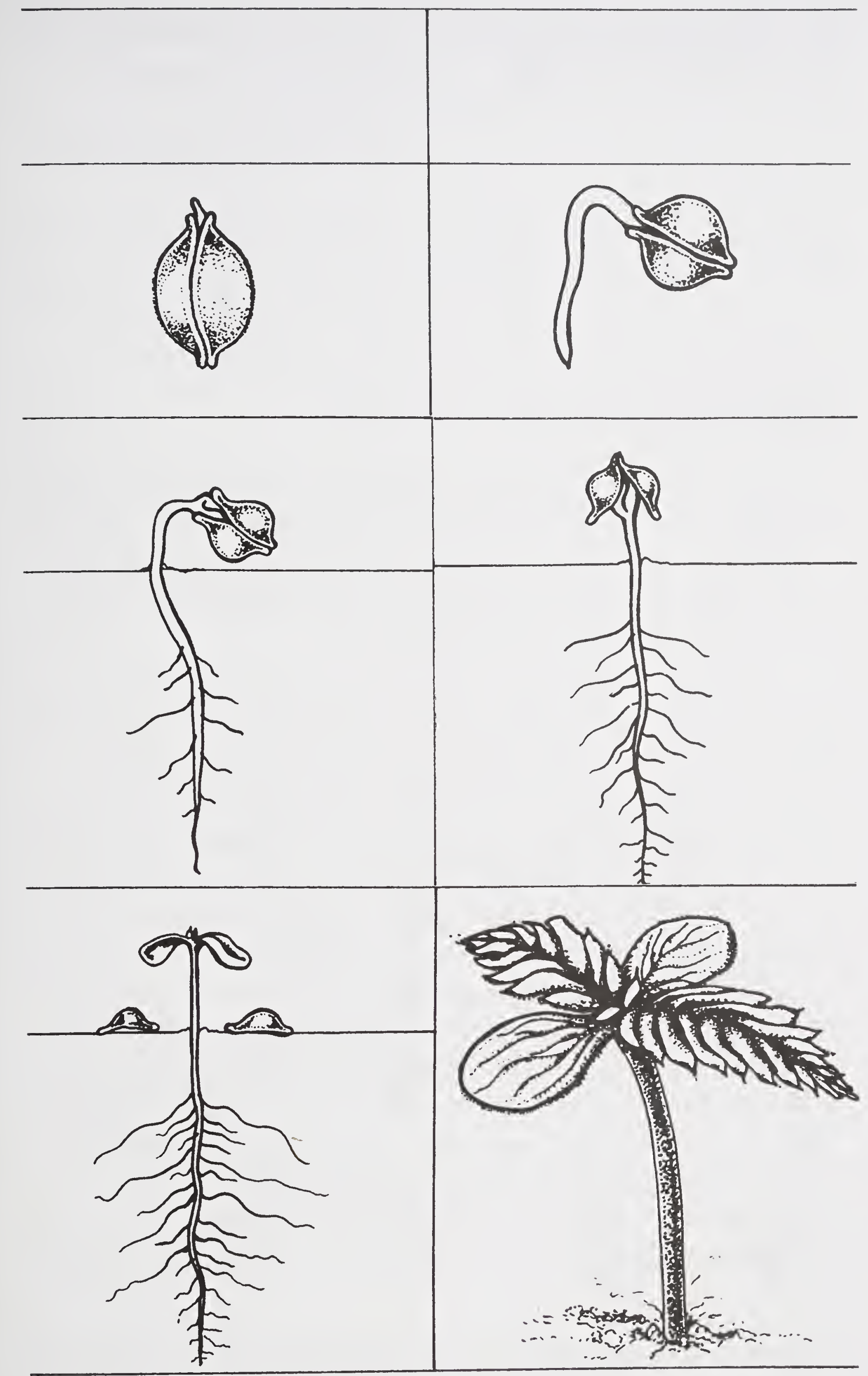




\section{Transplanting}

\section{Transplanting Seedlings in Peat Pots}

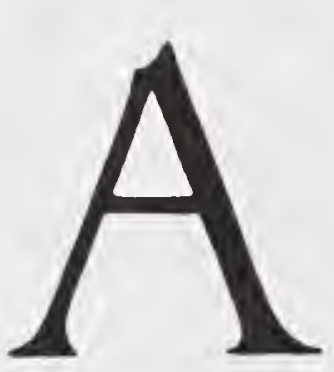

STROLOGY FANS, CHECK YOUR MOON SIGN. * The ground should have been prepared in advance $\&$ any construction finished. Get a bucket of manure tea (see page 50) or fish emulsion, \& the hose or watering can.

Scoop a spot in the center of the prepared area big enough for the entire pot. Now dip the pot in the bucket of tea briefly, then poke a few holes in it to make sure the roots can grow at the maximum rate. Set the pot in the hole deep enough to cover the edges of the pot completely. Gently press the pot into the soil, then water. Let the hose run on the ground, or pour water carefully around the seedling. Water until the area is well-soaked.

Make the entry on a map of holes in your notebook, recording the number, seed type, \& location as soon as you transplant. The original labels often disappear \& the map is a fine backup system.

After watering, press down all around the seedling once more to expel air pockets. It helps to be fairly methodical \& transplant the seedlings all at once, \& when you finish that, the heavy work is over. All that you need

\footnotetext{
${ }^{\star}$ Consult a reliable astronomical calendar or almanac.
} 
to do now is water them often \& enough, protect them from marauders, \& keep quiet.

\section{"Hardening" Indoor Plants}

Plants moved from indoors to outdoors need a two-week period of "hardening" so they can develop resistance to the elements - wind, cold, brilliant sun.

During the first week after the move outdoors keep them in filtered sunlight during the day, \& if it's not frosty leave them out overnight too. If frost is still a threat, bring the plants into an unheated room just above freezing for the night. In the second week place the plants in full sunlight, increasing the exposure by an hour each day. By the seventh day the plants should be able to survive full sunlight all day. If transplanted directly from a soft indoor

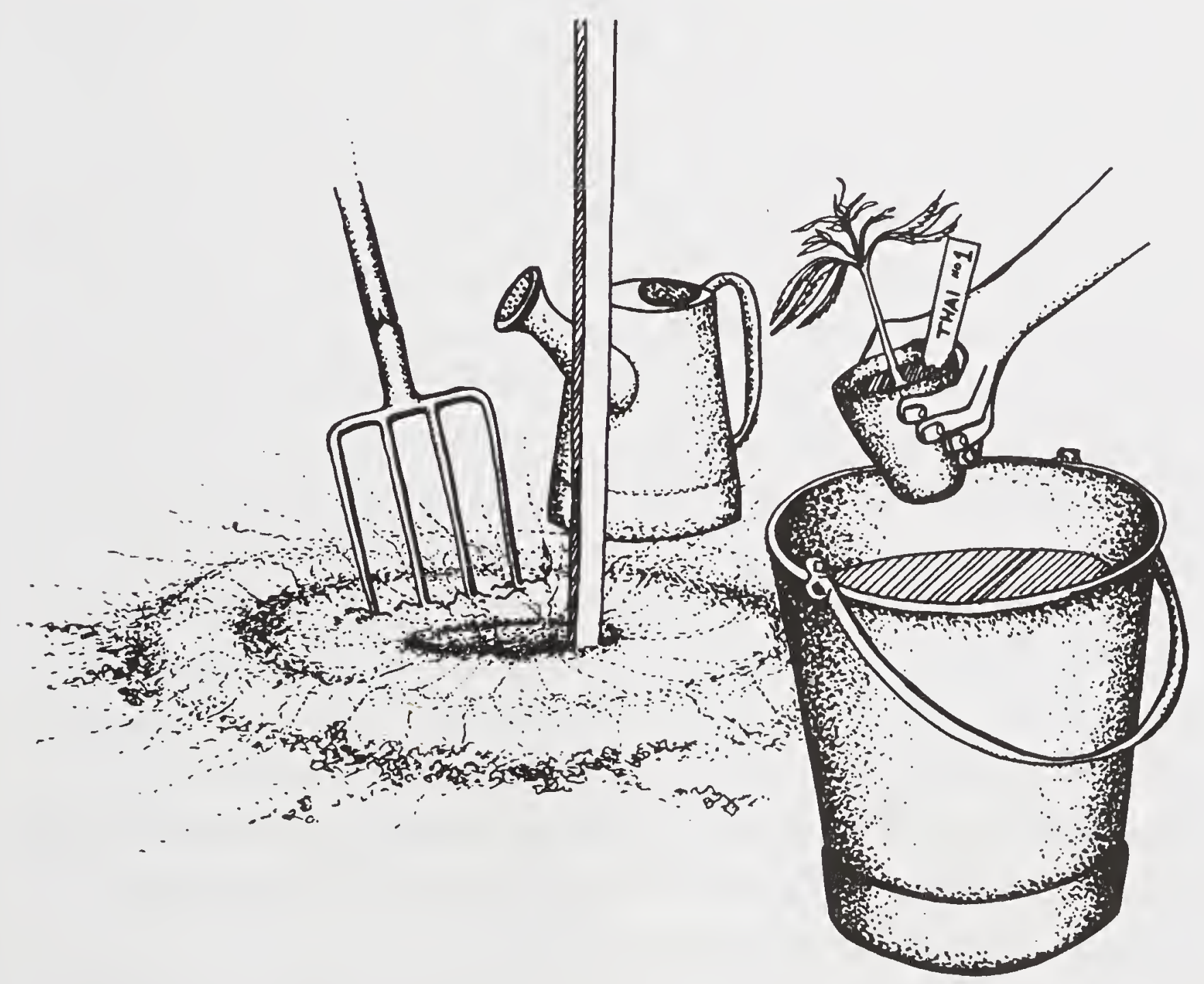

Soak the whole pot in compost or a fertilizer tea before transplanting 
situation to the great outdoors, many plants can be damaged by the intensity of real life, losing all their leaves \& suffering whiplash in the wind.

\section{Moving Larger Plants}

Some time may be necessary to transplant a large plant. Given the choice between killing the plant immediately in an immature stage or valiantly trying to keep it alive after transplanting, opt for the latter. If you really try, transplanting a full-grown plant is risky, hard workbut possible. One thing to note, though: Larger plants are too difficult to transplant in the heat of summer unless total shade is provided during \& after the move.

First have a place ready for the plant to go in a prepared hole nearby, a bucket, large can, bushel basket, even a fruit crate or cardboard box. Put in a large shovelful of compost to cushion the roots. Using a good, sharp spade, dig straight down about 1 foot out from the stem. Step hard \& straight down until the spade is completely buried, then pull it straight up. Cut all the way around the plant in this way. When the circle is complete, dig in \& carefully push back on the handle to loosen the plant. Extra hands are needed to pull a root ball this size out in one piece, so get help. At least two hands should lift the 2 -foot block of soil plus plant out of the ground. Support the soil ball underneath with the shovel carrying the weight of the foliage by holding the stem. Place the soil ball into the container or new hole immediately with the plant as upright as possible. Every caution must be taken to do no more damage to what's left of the roots. Just fill the corners \& top off the containers with sandy compost \& water the poor thing well. Mist it if the air is hot \& dry. Stake it up if wind is a possibility.

Keep the plant in the shade for a few days, gradually 
increasing the sunlight. Water it deeply \& frequently, \& feed it plenty of compost tea (see page 50 ) until the plant perks up \& begins to look normal again.

Transplanting small, actively-growing plants up to 2 feet tall is not too dangerous. Choose a cool cloudy or rainy day, early evening, or nighttime. Dig straight down 6 inches from the stem in a 2 -foot plant, using two hands to lift out the plant with a large root ball. The plant will go into shock for at least a week after being moved, drooping \& moping, but with plenty of water it will recover.

Transplanting smaller plants is also easy, just remember to dig straight down \& remove as large a ball of soil as possible, provide shade and water, and a little dose of compost tea to ease the pain of severed roots. 


\section{Sensible Feeding}

T F YOU PREPARED YOUR SOIL RIGHT, or if yOu planted in naturally fertile soil, the plants won't really need extra food to grow \& mature. But if you want to grow really amazing plants, some fooling around with various fertilizers is entertaining. Marijuana is tremendously responsive to good treatment. The aroma of the plants seems to be heightened by composting fresh materials continually around the plants' bases.

The seedling won't want any extra feeding. The root system is encouraged to develop rapidly in the sandy starting mix, in the search for scarce food.

The two-month-old plant can survive on what's been dug in, but will grow more rapidly if you regularly feed it compost or manure tea in light doses. (See page 50). Fish emulsion \& kelp extract are excellent organic fertilizers that can be poured on after watering.

The rapidly growing larger plants appreciate nitrogen feedings all summer long. A heavy mulch of manure, compost, cocoa bean hulls, or other rich nitrogen food can be heaped around the bases of the plants. Growers trip out here. Madmen apply carrot pulp, orange peels, rose petals, rabbit manure, deer shit, anything you can name that might rot. Lighter materials are heaped up to conserve 
water \& aid decomposition of whatever you use.

The result is an incredibly alive soil around the base of the plant. Earthworms will appear to munch the goodies \& flourish madly.

As the plants begin to bloom, stop feeding them nitrogen-rich nutrients. Work in some bone meal \& white wood ashes at the bases of the plants \& water them in well. A mulch of crushed oyster shells may be laid around each plant. These will boost the available potash \& phosphorus, promoting large, well-formed flowers.

The three major plant nutrients are nitrogen, potash, \& phosphate, \& there are many trace elements also essential for plant health. Several organic \& natural fertilizers supply these nutrients in balance. Organic fertilizers are manure, sewage sludge, compost, \& kelpall derived from living things. Natural fertilizers are limestone, potash rock, phosphate rock, granite dustall naturally occurring, crushed rocks.

Chemical fertilizers are also rock powder, but have been treated with strong acids to make them instantly soluble. Superphosphate is half sulfuric acid. These fertilizers are definitely too strong for marijuana growing.

\section{Composition of Fertilizers}

Manure: Fresh manure supplies nitrogen, smaller amounts of potash \& phosphate, \& biological activity.

Fish Fertilizer: Strong nitrogen, lots of trace elements.

Dried Chicken Shit: Strong nitrogen, strong phosphate, strong potash.

Sludge: Available commercially as Milorganite; rich in nitrogen, phosphate, \& trace metals.

Cottonseed Meal: Rich nitrogen.

Bone Meal: Phosphate \& calcium, a little nitrogen. Kelp: High in potash, valuable for trace elements.

Wood Ashes: Potash; has alkalizing effect; mustn't 
get wet before use.

Limestone: Chiefly used to alkalize soil, also adds calcium.

Crushed Oyster Shells: Calcium, has liming effect.

Potash Rock: Potash \& trace elements, is longlasting.

Phosphate Rocks: Phosphorus \& trace elements, is long-lasting.

Granite Dust: Some potash, is long-lasting.

All these can be dug in at planting time or before. If the soil is loose \& penetrable, the plant can be fed liquid fertilizers. No amount of extra food will help a plant stuck in hard, compacted soil.

The simplest \& most foolproof feeding technique for the organic cultivator is using manure or compost tea; commercial organic fertilizers are effective but expensive.

\section{Fertilizer Recipes}

Use these only after the regular watering. Water is as important as the food: the roots can't absorb nutrition except in the presence of water.

Manure Tea: Soak $1 / 4$ bucket of old manure or $1 / 8$ bucket of fresh manure in a full bucket of water. Stir well, dip out liquid. Use 1 quart per large plant, 1 cup for a baby. Manure can be soaked three or four times.

Compost Tea: Soak $1 / 4$ bucket of rough compost in 1 bucket water; use like manure tea. Bucket can be refilled with water several times.

Yuck Soup: Half fill a bucket with weeds or grasses \& garden trash; soak with water overnight. Can be reused a few times. Use as manure tea. 


\section{Creating The Perfect Environment}

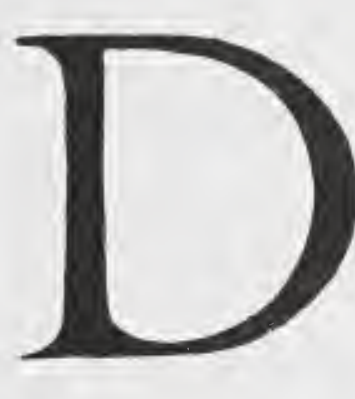

ON'T GIVE YOUR PLANTS A HARD TIME, it WOn't make better smoke. Disregard any advice about starving, dwarfing, making bonsai, torturing, or not watering to create difficult conditions. You can get just as busted for 2 -foot sick plants as you can for 10-foot giants, so grow for peak production \& health, as you would with any prize vegetable. The result of maltreatment is reduced yield.

After transplanting \& until flowering time, the rapidly growing plants require lots of sun, careful watering, plenty of growing room, \& very little attention. This is the vegetative stage, time to take a vacation.

Some soils, sandy or gravelly in origin, dry out much faster than heavier clay or loam soils. When the weather turns hot \& windy, increase watering. Otherwise, with regular summer rains \& adequate soil, watering will be unnecessary. Hot drought areas, greenhouses, \& container gardens call for plenty of extra water.

Until the young plants reach 2 feet tall, they should be watered three times a week, thoroughly. After the plants pass 2 feet, water deeply once a week. The soil should be wet $1 \frac{1}{2}$ feet down.

Check the soil before \& after watering, to see where the water is going. Dig a little hole between the plants with 
a trowel once in a while to make sure the water is going down, not away. Don't let puddles form near the plantsstanding water will suffocate \& kill the roots in a few hours. Roots need air to live.

Dragging the hose around can be tricky, so work out an easy watering method. A soaker hose works well or a low lawn sprinkler to make rain. Don't stand with the hose slopping water on the roots; squat down \& lay the hose on the ground, letting the water soak down slowly. It helps to make a shallow moat around the bottom of the plant \& pour the water into that. Be careful not to walk on the soft soil around the plants.

There is no way to state exactly how much water to use. A very hot, dry garden may require 2 gallons of water per large plant, more if the surrounding soil is sandy. A cooler, damp location with low nighttime temperature will need much less.

Containers dry out very fast, especially wooden or unglazed clay pots. When watering, be sure to spray the outside of the containers too.

A thirsty plant will droop-then wilt. It will continue to draw water out of the roots until the roots wilt, causing irreversible damage. A badly wilted plant should be misted immediately to stop transpiration, then slowly watered to save its life. Baby plants are easily injured \& stunted. Adult plants survive dryness if the subsoil is still damp around the taproots.

All gardeners recommend watering in the morning to let the plants dry off before nightfall.

Young plants \& container specimens love warm water. All marijuana farmers agree that the best way to mature good grass is in a warm, dry soil. Once blossoming has fully begun, allow the soil to get dryer \& dryer slowly, but not to the point of wilting the plants. As the weather cools they need less watering anyway. 


\section{Part IV}

Pruning \& Plant Care

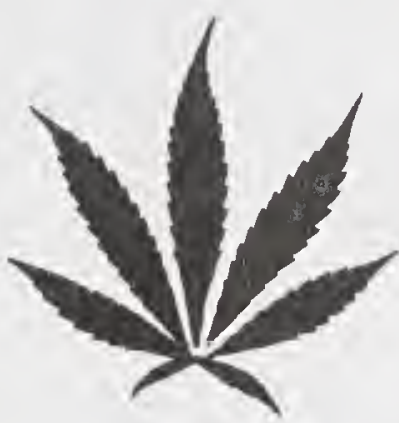




\section{Pruning}

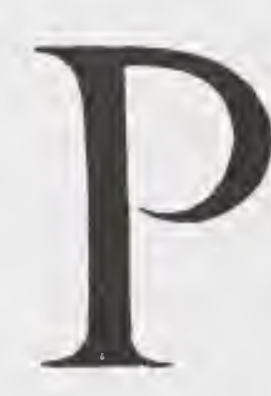

RUNING IS THE CUTTING OUT of unwanted parts of a plant to benefit the rest of the plant. It's not a mysterious process, but one based on reason, \& it is not essential for growing high quality marijuana.

Frequently animals will accomplish this difficult choice of action in your absence, \& even the most nibbled stump will eventually regrow if a portion of the leaves remain.

Don't prune the plant unless you have to, \& always do it on a hot sunny morning to give the sun a chance to disinfect \& seal the wound. Cutting into the plant during rainy or damp cold weather causes the plant to bleed, or lose fluids rapidly.

The best, most convenient tools for pruning are the thumb \& forefinger. Pinching off the tip of a rapidlygrowing plant slows the upward growth \& forces the branches to spread out strongly.

Some pot plants shoot straight up without branches, especially in crowded or shady situations. These should be pinched back early, before the plant reaches 18 inches. Other plants grow all their branches from the start \& don't need early pinching. This early branching is a female trait, 
This young plant needs pinching to encourage branching (6 weeks)

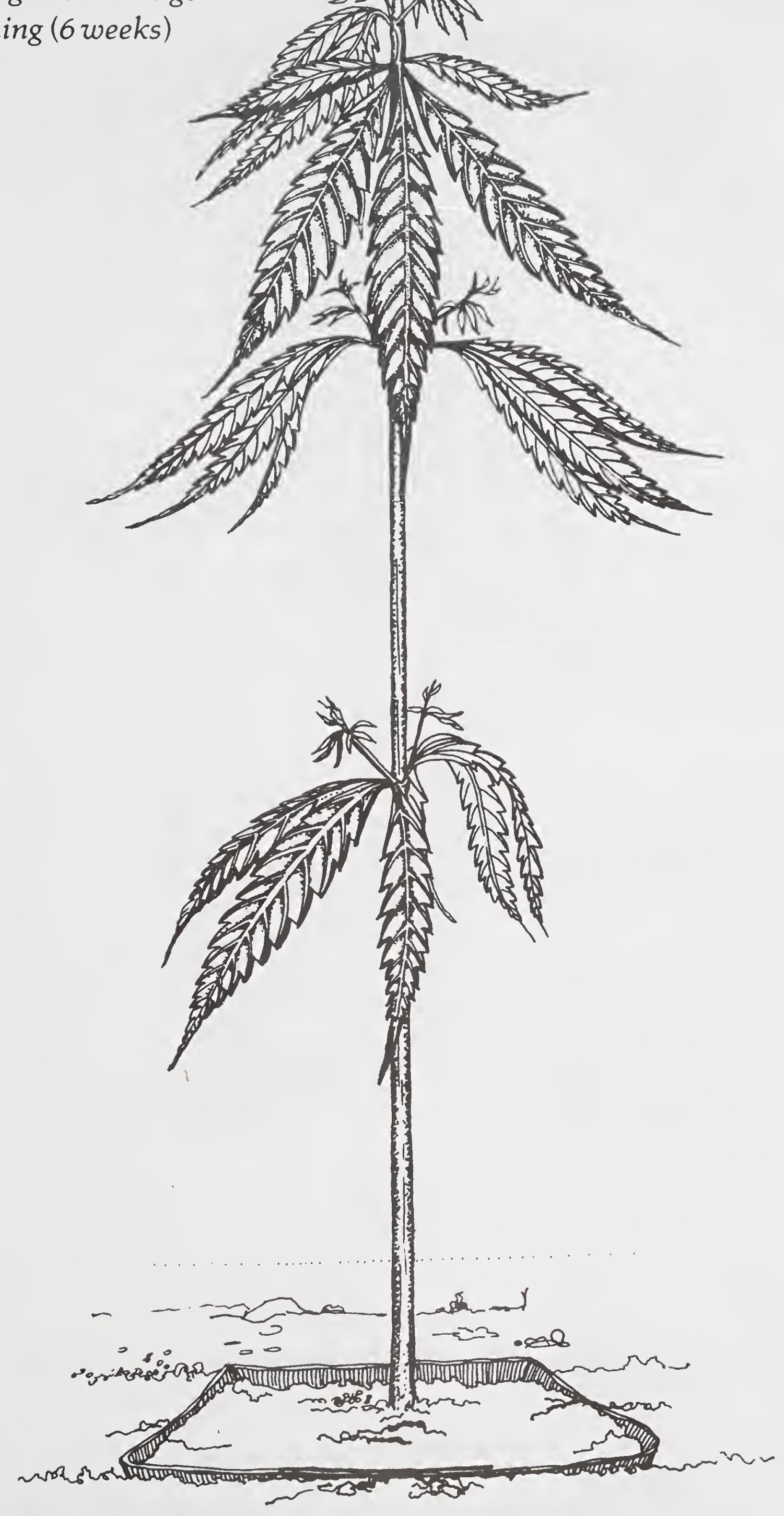




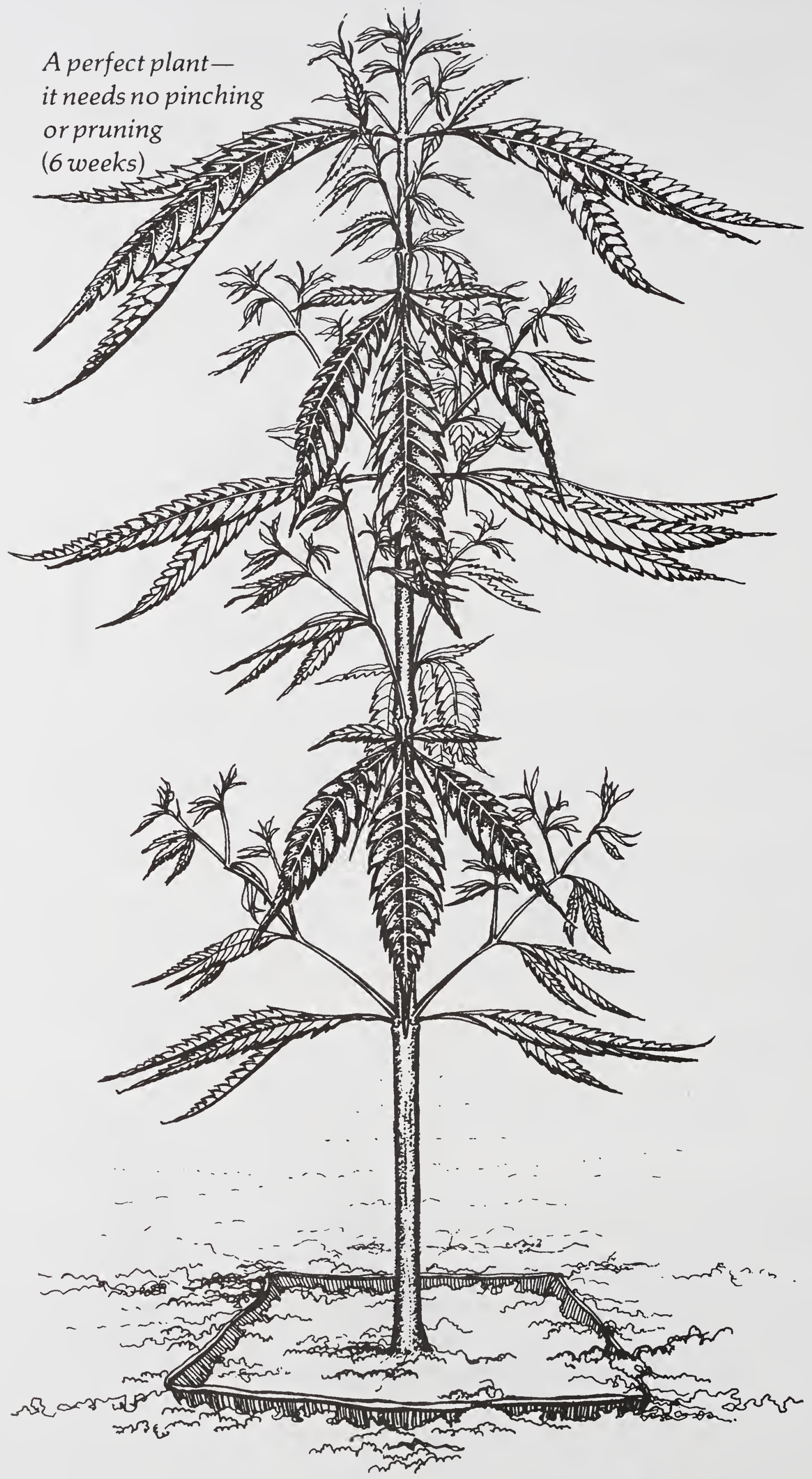


of value to the breeder, making a short, wide, less visible plant.

The naturally grown outdoor plant makes its main growth in June, July \& August, sometimes growing an inch a day. You will notice that the large leaves usually grow in pairs at even intervals. This symmetry is broken late in summer when the plant grows angled stems with only one leaf per joint. In response to solar decline in midAugust, the plants begin growing flower stems on these newer stems. The smaller, angled flower stemlets, 2-6 inches long, form at each leaf joint. Once the flower stemlets appear, no major pruning should be done.

Plants grown where height is a problem, such as a backyard or patio, may need repeated pruning in late summer. To reduce the size of a 6 foot plant, or one that's growing too fast with large empty spaces on the main stem \& branches, cut off a foot or more of each main branch \& 2 feet off the main stem. This is an act of violence \& should be done only if absolutely necessary.

Instead of cutting, a careful grower can weight or tie down the long branches into a horizontal direction of growth. This increases the amount of flowers a plant can produce.

The stems of very fast growing flower tops can be bent over until they snap but do not break. The tops will continue to grow-sideways. This is radical, but it is better than severe pruning just before blossoming.

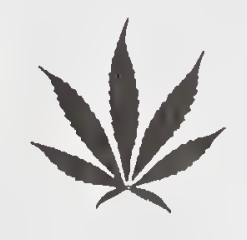




\section{Pinching}

With the thumb \& finger pick off the tiny, soft growing bud at the very end of the main branches \& main stem. This can be repeated later if the plant still isn't full \& bushy. Pinching is much less traumatic than pruning, but overpinching will result in a profusion of tiny weak branches, not at all desirable for large flower clusters.

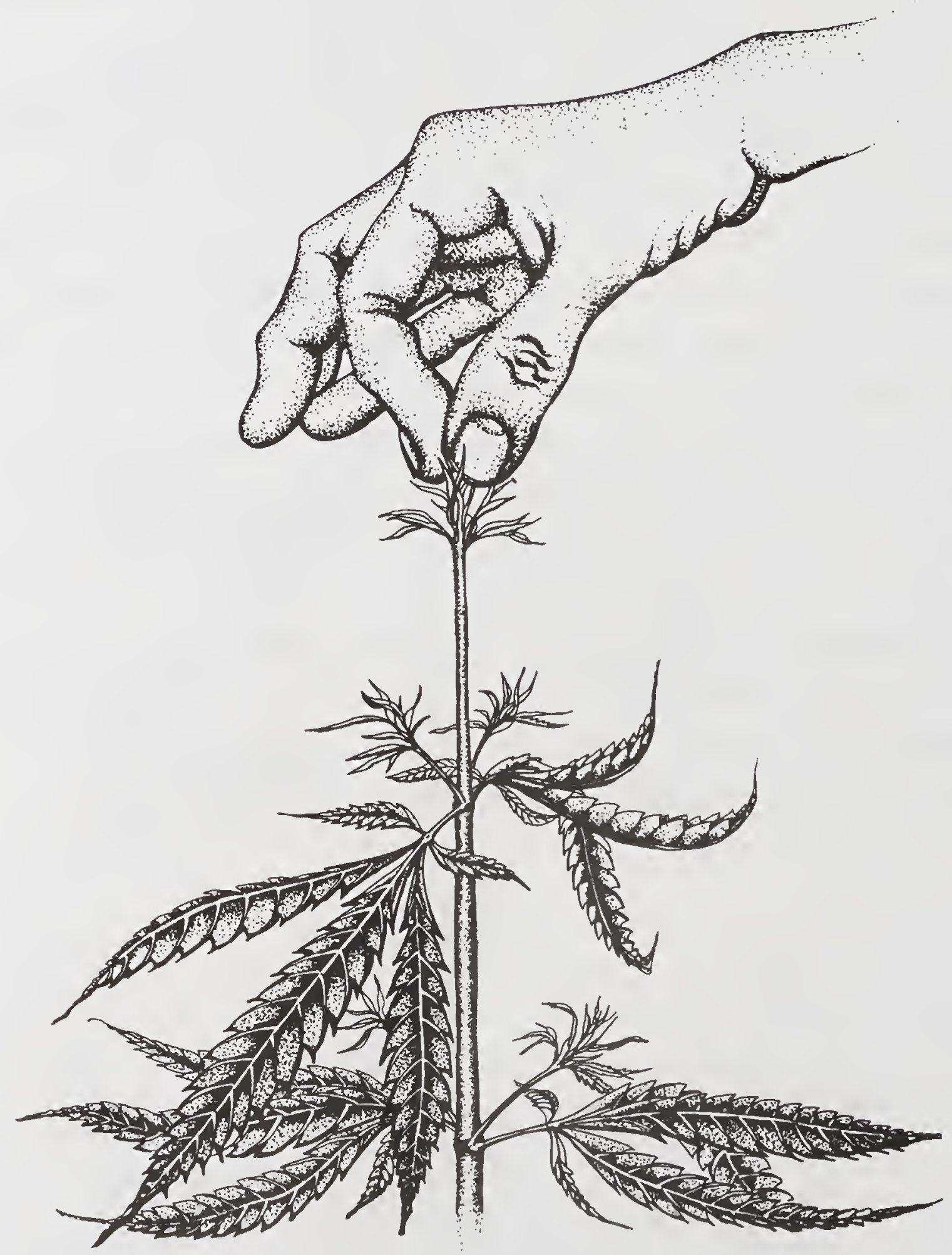




\section{Cutting:}

Use very sharp pruning shears or scissors for a clean, fasthealing cut. Always cut back to $1 / 4$ inch above a leaf axil, the point where the leaf stem joins the main trunk or branch. New growth will start from this joint. In damp, cool, or shady areas, treat the wounds with rubbing alcohol \&/or Tree Seal. The ends of branches that you cut off can easily be used to make cuttings (see page 61).

Keep in mind that every time you cut or otherwise injure your plant it is forced to heal itself \& that infection can start at the cut.

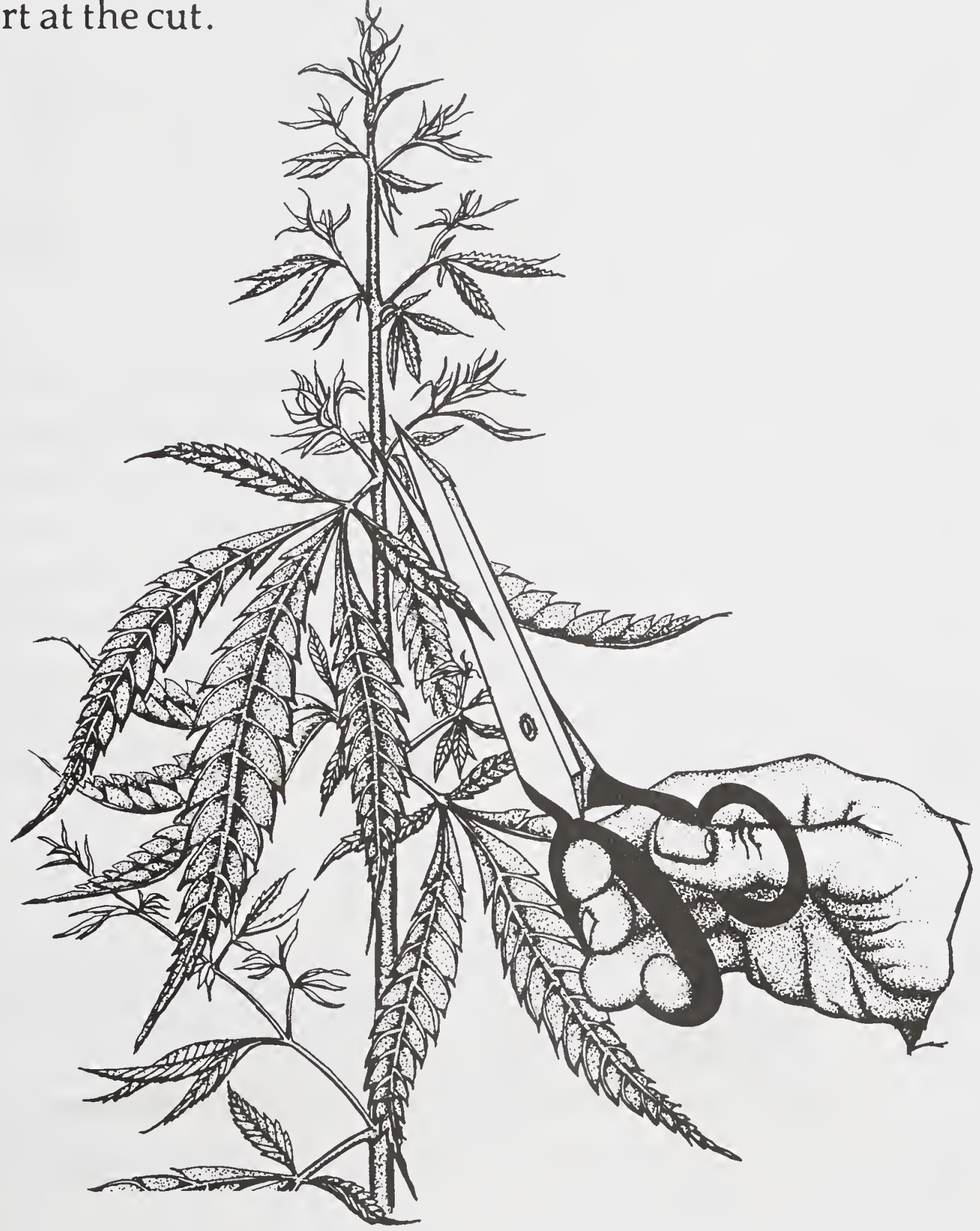




\section{Other Techniques}

This is a popular subject in dope-growers' circles.

You can heavily prune very young plants in the ground outdoors, much like a rabbit munching off the tips of the branches. This creates a dense, tiny plant. Its stem then grows thick \& short, with giant branches erupting at ground level. Repeated pinching creates a dense stout plant that resists rain \& wind damage. Plants must be very widely spaced to maximize spreading.

Some folks recommend picking off all the large leaves. "Shade leaves" they call them. Horseshit. These large leaves are your solar factories. The more square footage of leaves a growing plant has, the more solar energy it can gather to turn eventually into flowers \& seeds. The plant doesn't feed the leaves, the leaves energize the plant. Leave them alone. That's the reason female plants spread out wide, to gather maximum sun.

Another oft-heard theory is that picking off all the large leaves a few weeks before harvest will stimulate or change resin production, or cause larger flower clusters to develop. Little harm is done by this technique, \& it saves time later, after harvest. The process is similar in nature to snails \& insects attacking the oldest leaves first, cleaning out the center of the plant. I have not noticed any improvement, however, in the final product. It's my opinion that leaf pruning is unnecessary, \& harmful to growth if done before the blossoms are formed.

If you want to break off large leaves shortly before harvest \& save a lot of energy later on when dealing with the dried plants, try to develop a controlled "snap" that cleanly breaks the leaf stem off at the junction. Breaking or cutting leaf stems in the middle will leave stumps that rot.

Plants grown under perfect conditions \& allowed to develop their full potential should never need any pruning or trimming of any kind. 


\section{Rooting The Cuttings}

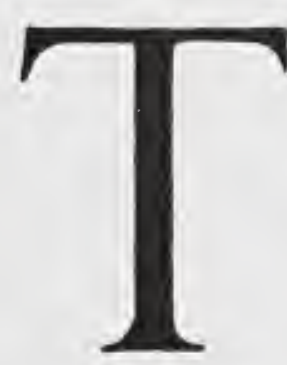

HIS SIMPLE TECHNIQUE CREATES many out of one. A growing plant may be pruned \& the tips of the branches rooted to grow new plants identical to the mother plant.

A 4 inch section is cut from the end of an actively-growing branch. Trim off the bottom set of leaves with a razor blade, cutting the stem on an angle. Bury the bottom half of the cutting in a damp mixture of 50 percent vermiculite, 50 percent sand. Mist the cuttings several
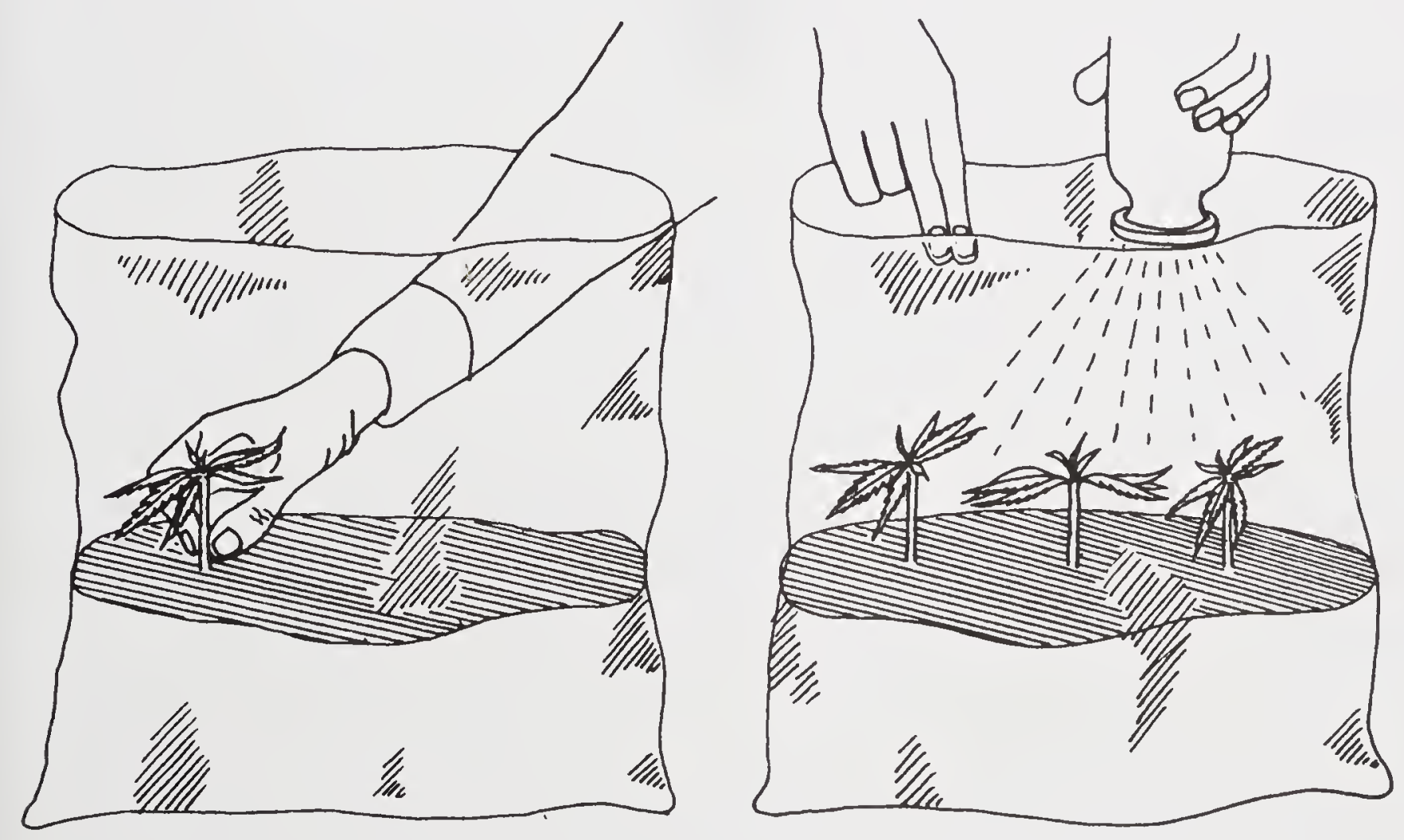

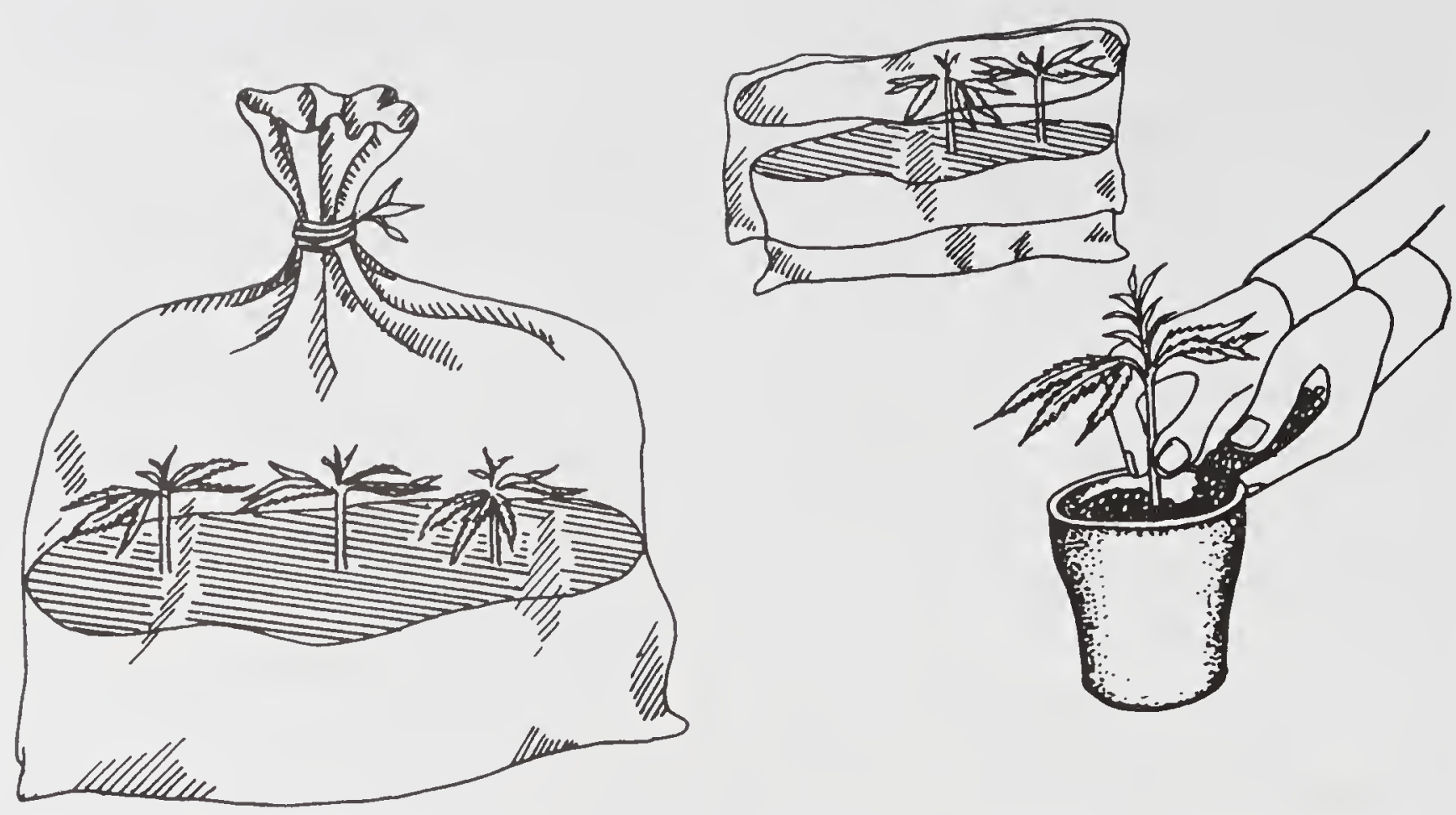

times a day \& keep them in a cool, shady location. You might want to root the cuttings in clear, plastic containers so you can see the roots grow. Roots begin to appear in two to three weeks, and when they are strong, new growth begins above. Be sure to keep them cool \& moist, \& somewhat shaded to prevent shock \& wilting. Transplant the new plant when it has doubled its original size. Expect a 50 percent survival rate.

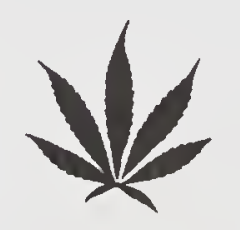




\section{Part V}

Flowering

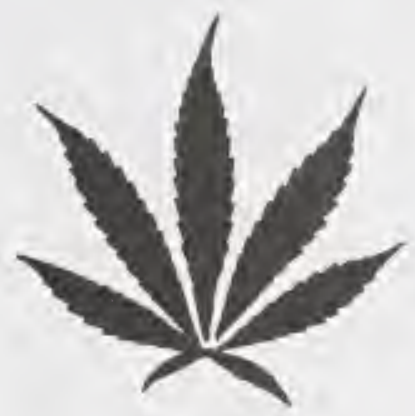




\section{First Flowers}

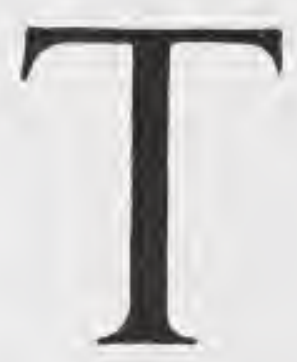

HE FIRST SIGNS OF A PLANT'S SEX often appear on the main stalk about two-thirds of the way up. Inside a leaf joint, where one of the big leaves joins the stalk, a tiny flower or flower cluster will appear long before the flowers on the tops.

If the flower is male, it will first resemble a miniature crab claw or a tiny bunch of bananas. As it prepares to open, the largest banana will protrude from the cluster, develop a stem, \& actually look like a tiny flower bud. When it does open, it dangles, gives off yellow powderthe pollen, \& looks like a tiny greenish flower, about $1 / 2$ inch wide.

If the first flower is female, it will look totally different. First it appears as a tiny rolled up leaf $1 / 4$ inch long. A few days later, two small white feathers stick out of the pointed, unattached end of the little rolled leaf that is the future seed jacket. The feathers on some plants stay small $\&$ almost colorless. On other plants they will reach $1 / 2$ inch \& turn a dazzling snow white. The little feathers are branches of the pistil seeking the pollen blowing in the wind. They are attached to the ovary, hidden inside the green flower.

These early flowers are tiny \& often hard to find, \& frequently there is only one early blossom on the whole 


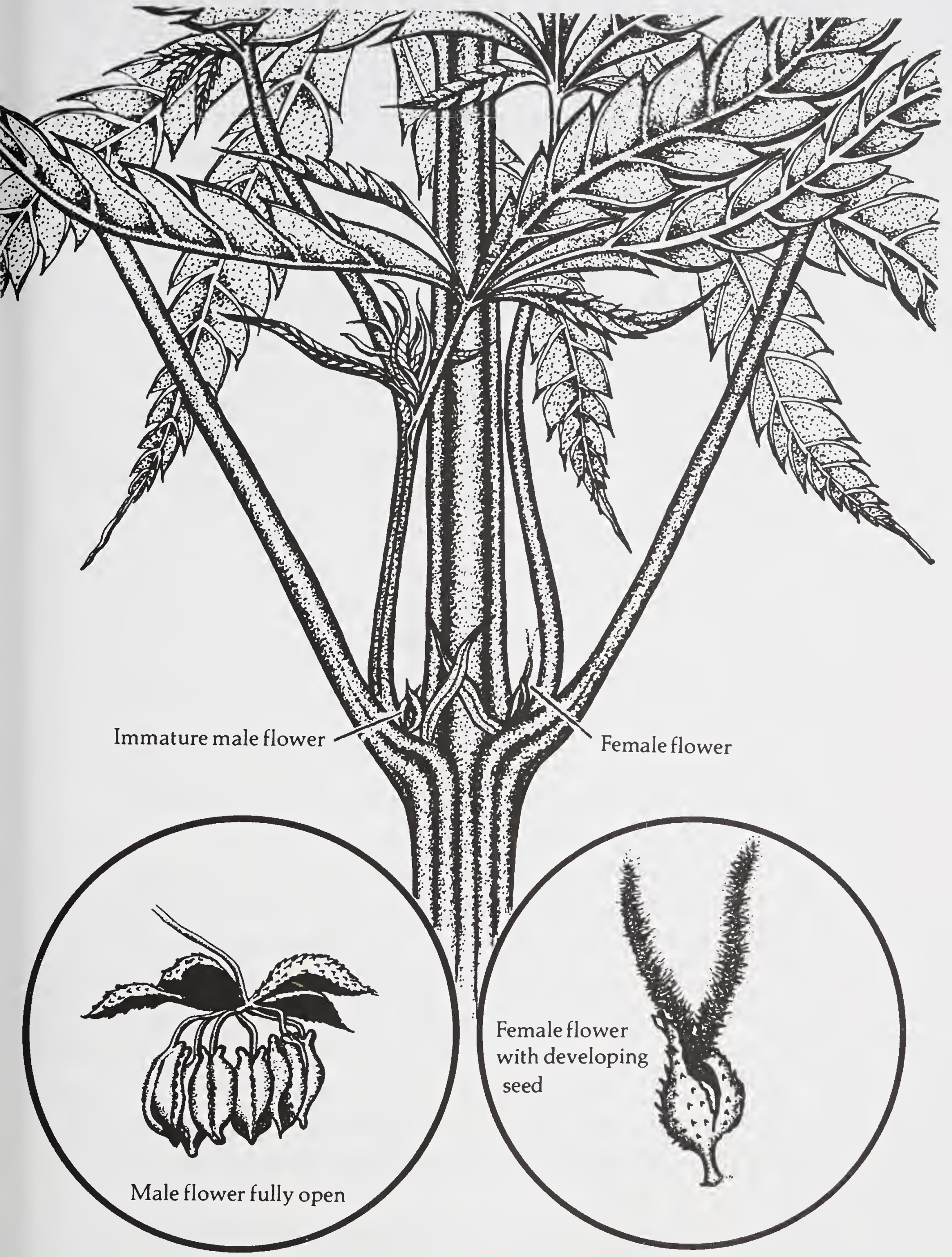

Early flowers appear in the joints on the main stem 
plant. If your plants are crowded at all, get in there \& hunt for these early indications. If you can find one female flower complete with feathers, that plant will definitely be female, so mark it with something bright.

However, some plants never show these early flowers, so watch the growing tips for main flower growth. In the male, you'll first see rounded clusters of tightly packed, broccoli-like buds; a lot seem to form at once. In the female, development is less rapid; watch the leafy tips for white feathers in ever-increasing numbers.

Hermaphrodite plants have both male \& female * flowers mixed together, and they develop in the shadier, more difficult growing spots. Cannabis is bisexual only when threatened, retaining the ability to make both kinds of flowers all its life. 


\section{Sex Discrimination}

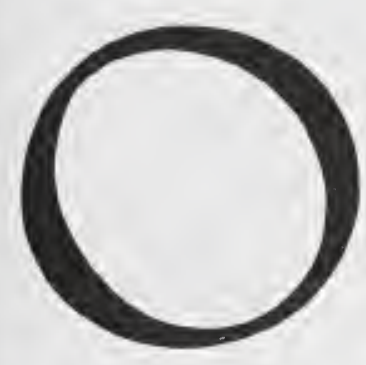

UTDOOR PLANTS START TO MAKE FLOWERS about the middle of August in response to the shortening days. By September 1 it is possible to tell clearly the sex of the plants. Decreasing hours of daylight encourage the plant to bloom, \& any extra light shining on the plants at night will delay flowering, as will cold temperatures during the day.

If you are not concerned with breeding or seed production, leave the plants to flower \& create seed without worrying. Male plants, which are not very good to smoke, will bloom \& die. You can use them to make extracts or pot butter, or as placebo smoke.

The tightfisted grower will want to remove the male plants early to leave extra light \& space for the stillgrowing females. Male plants begin blooming heavily the last week in August, \& daily close attention must be given to prevent chaotic seed making. This means going to the garden each day \& looking at the growing tips of each plant for signs of flowers. Male blossoms usually cluster at the tops of the plant. Gently separate the leaves \& examine what's growing there. Male buds resemble broccoli buds, clustered football-shaped green buds about $1 / 4$ inch long. The largest buds open first, releasing yellow pollen into the breeze.

On later days, more of the buds open until the plant is covered with little dangling dusty flowers. Cut the males 
back to the ground or leave a bottom branch for pollination purposes if the plant is desirable for parenthood. In the female, development is less rapid; watch the leafy growing tips for white feathers in ever-increasing numbers.

Some plants will make a few small blossoms very early, down on the main stem at a leaf joint. These early flowers do not indicate the final sex of the plant, but seem to occur most frequently on female plants. Females often produce one or two male blossoms along the main stalk in August, while male plants rarely produce female flowers. Often a male \& a female flower will grow next to each other at the same leaf joint. This apparent bisexuality can be used to produce an all-female strain of seeds. (See hermaphrodite, page 74 .) 


\section{To Seed Or Not To Seed}

\section{Ll pot Fans have heard of Sinsemilla. This translates to "seedless." Sinsemilla is a female plant grown to full blossoming maturity with- out any male pollen reaching it. No pollen, no seeds. Why is this desirable? Seeds are the}

final, ultimate purpose of marijuana life, so the strong female plant will make as many as it can (if you let it). Pot seeds are high in proteins, fats, and stored sugars to start that baby plant. The plant will spend its entire store of nutrients \& energy making pounds of seeds, not resin.

Seedless or very slightly seeded plants make many more flowers, with a much stronger high \& a sweeter taste. Plants grown this way will continue to produce new flowers every day at the tops of each flower cluster until the tops are huge. Plants that have been heavily pollinated seem to stop growing new flowers right away, \& throw all their energy into seed making.

A few seeds are a good idea, two or three per top. It helps the plant remain convinced of its femininity, assuring next year's crop in case the plant is "The One." It is truly entertaining to begin crossing favorite types \& this is where the labels pay off.

To select a male parent, pick one with strong, wellbranched stems \& healthy appearance that is also an early 
bloomer. Cut if off, leaving one branch on the stump to bloom. Before the male flowers open, put a plastic bag around the plant \& fasten tight. You can reach in later, pull off a few pollinating flowers, \& blow pollen on a few

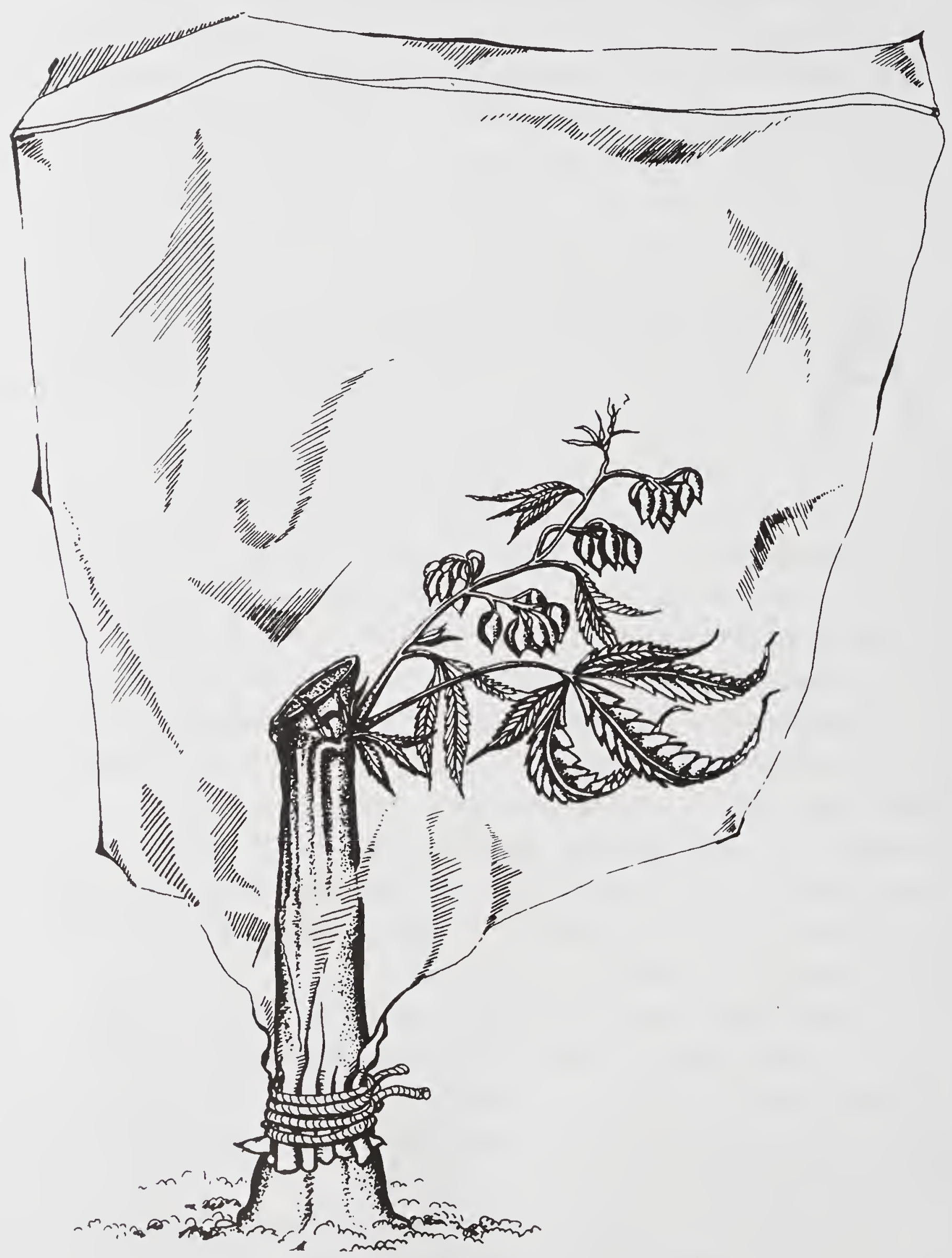

Store valuable pollen in film cans 
select females - only the bottom flowers should be fertilized to carry the seeds. It's wise to do this well before harvest when the females are just starting to bloom heavily, giving these few seeds a long time to mature.

A favorite trick of the sinsemilla plant is to grow one tiny male flower or part of one at the very tip of a main flower cluster. Sharp observation daily will turn up this little yellow banana. Pick it off. It doesn't seem to appear until the end of the growing season, just before harvest. That little male flower is your plant's stab at perpetuitya female so hungry to reproduce that it can manipulate its hormones to fertilize itself.

The virgin sinsemilla plant waits \& hopes, each day producing new flowers. The older flowers swell, the white feathers change color to gold or even rose-pink. The calyxes, or seed jackets, thicken \& develop a heavy layer of resin in droplets visible with a hand lens. The flowers may change color to deep red, purple, or a rich yellow. If pollen from a male still isn't forthcoming, the little flowers shrivel \& turn brown. The smell knocks you down with its sweetness. The big leaves droop, turn yellow, \& start to fall off. A slight gray tinge develops over the whole plant. A seeded plant will follow the same pattern as the seeds begin to mature. 


\section{How To Grow All Female Plants}

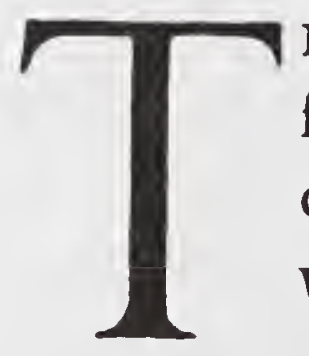

HIS METHOD IS SOMEWHAT TRICKY \& isn't easy for first-time gardeners. Anyone who has ever done serious flower \& vegetable gardening will find it relatively simple \& error-proof.

The seeds are planted in spring either in pots or a special planter box, or outdoors in a special raised bed or cold frame. Put in plenty of seeds - the young seedlings can be thinned to stand 3 or 4 inches apart-\& grow these in the normal manner. Plenty of strong light during the day with protection at night from frost is necessary. Don't feed them \& take care not to overwater or underlight.

When the young plants are about a foot tall, subject them to deliberate light deprivation. Cover the plants with a large cardboard box (or move them into a closet) to completely shut off all light for sixteen hours at night. During the day, light the plants for only six hours. This means taking the box off at $10 \mathrm{a} . \mathrm{m}$. and replacing it at 4 p.m. every day for two weeks.

After two weeks, look very closely: tiny blossoms will have appeared in the leaf joints on most of the plants. You will be able to clearly see which ones are female \& which are male. Cut off or pull out the males, saving the 
healthiest, strongest females to transplant into the permanent location outdoors or in the greenhouse.

To stop blossoming \& to return the plants to the vegetative growing stage, give them light 24 hours a day for three days. This is not needed if the daylight hours are 13 or more.

After transplanting, the plants rapidly grow to full size, maturing \& blossoming normally at the correct time."

This technique is perfect for small growers with limited space. The same technique can be used by indoor growers to bring small plants into bloom at any time, a method that will work with any plant over five weeks old.

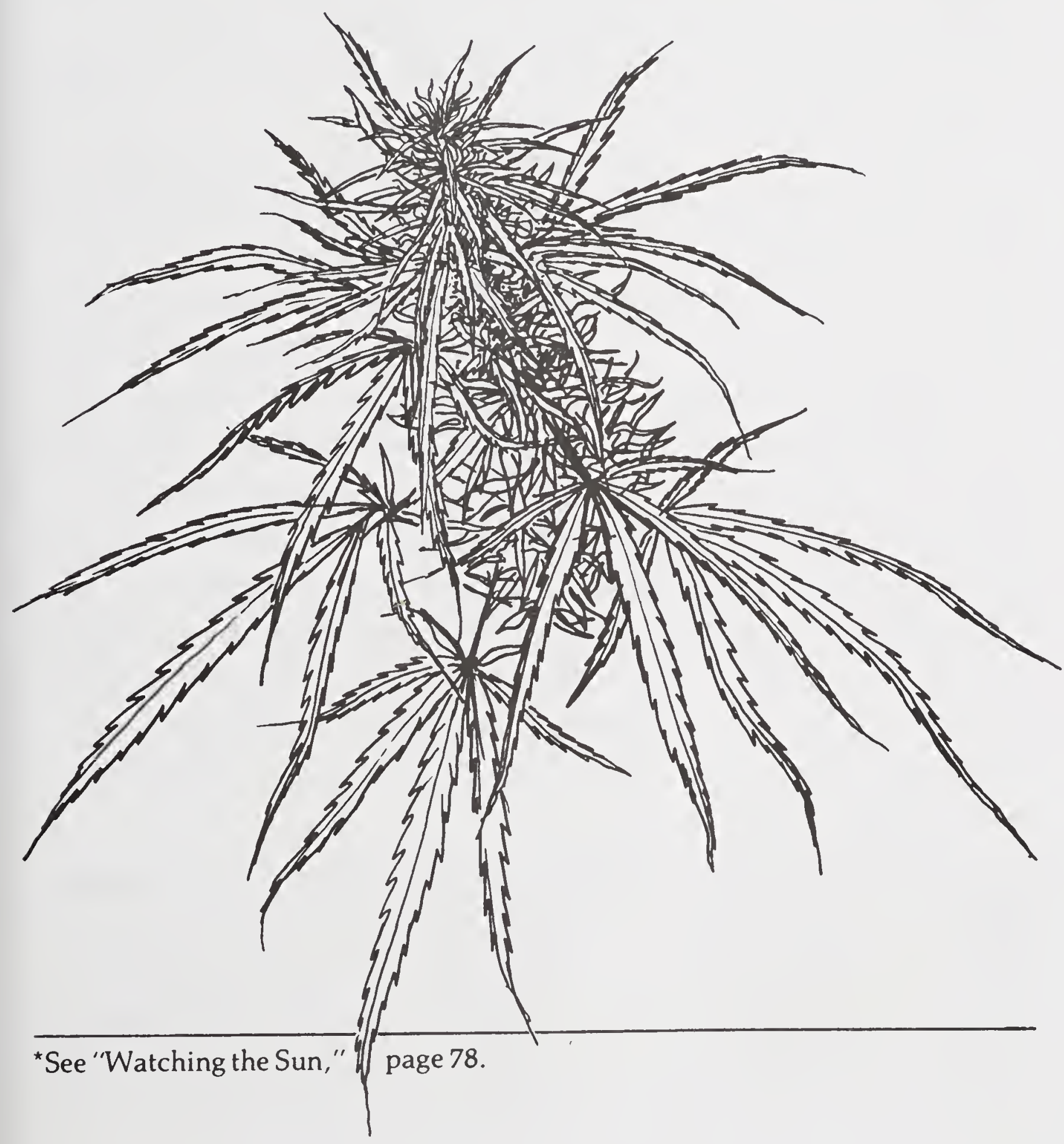




\section{The Hermaphrodite}

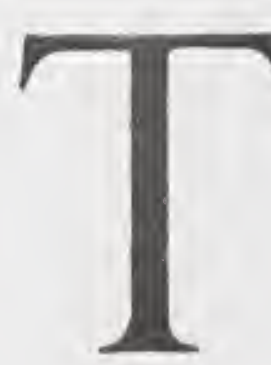

HE HERMAPHRODITE, or monoecious marijuana, is a pest if you are trying to grow seedless, but a gold mine for the careful breeder with an eye to next year's crop. Extensive scientific research has been done on cannabis "herms,"

\& their results are remarkably similar to those I came up with accidentally.

Cannabis is usually divided clearly into half male, half female plants. Under certain conditions-short days, high-nitrogen feeding, cool temperatures, \& intense lighting - many of the female plants will produce quantities of male blossoms. They will appear in clusters below the female flower clusters or will be mixed in. The plants are really females, \& the pollen produced from these male flowers is genetically short one chromosome - the one that produces masculinity. It is this quality which makes hermaphrodites so valuable to breeders. Cannabis behaves like humans-male sex is determined by the presence of a $y$ chromosome in the male pollen. Female plants produce only $x$ chromosomes, so a flower pollinated by "female" pollen is going to produce a seed that will grow only a female plant.

Male marijuana pollen, grown in the wild, is 50 percent male-producing, 50 percent female-producing. The first year of growing will probably produce this proportion. If you are lucky, you can grow a larger percentage of females, possibly because a previous grower was careful 
to remove male plants before they shed their pollen. Sinsemilla marijuana will usually have a seed or two, which are likely to be female-producing.

To cultivate hermaphrodites deliberately, subject the plants to shorter days \& strong nitrogen feeding.

Indoor growing could produce a strain of all-female seeds in the winter months before the main crop is established outdoors. By manipulating light, you can force plants to bloom \& seed in 6 to 10 weeks indoors. By careful control, the all-males can be removed, leaving the females to pollinate themselves \& produce all-female seeds. (See the previous section.)

Hermaphrodites occur more frequently under difficult growing conditions, such as shady areas, cold weather, shorter days, \& nitrogen overfeeding. Wintergrown plants in the greenhouse will show more male flowers than plants grown in summer with long days \& warm air. It is the hot summer with long daylight hours that seems to develop clearly sexed plants with no intersexual flowers.

Does the hermaphrodite get you high? Yes, \& the bonus of female-producing pollen is a great gift to the small-time grower with limited room.

Sometimes hermaphrodites will produce such an abundance of male flowers that sinsemilla is out of the question. To avoid this, pick off the largest male bunches before the flowers open. This is time-consuming, but worth it. Plenty will escape your notice \& pollinate some flowers anyway. If too many male flowers appear all at once, as a last resort, transplant to another area. Even very large plants can be transplanted with partial success if great care is taken (see page 46).

Researchers say that some types of pot have strong hermaphroditic tendencies while others say not. Marijuana genetics is still largely unexplored. 
When the very first female blossoms appear on the main trunk of the plant, pollinate them. These tiny blossoms are always the first to show, \& if they are touched with a fingertip coated with real male pollen, the entire plant receives the signal. This must be done early to be effective. It is also a potent signal for the main blossoming to begin.

The large flower clusters at the ends of each branch remain seedless but satisfied, while only the tiny worthless single flowers on the main stem carry the seeds.

Male pollen may be kept in a small container, a film can for example. It remains active for a long time if not overheated. 


\section{Part VI}

The Harvest

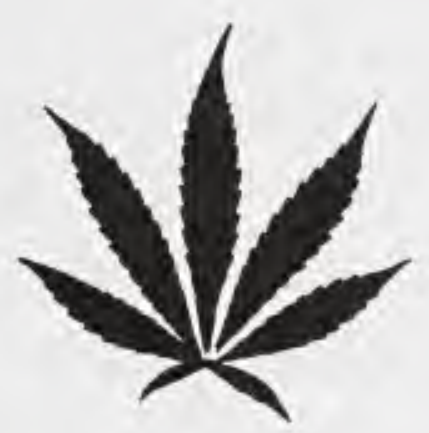




\section{Watching The Sun}

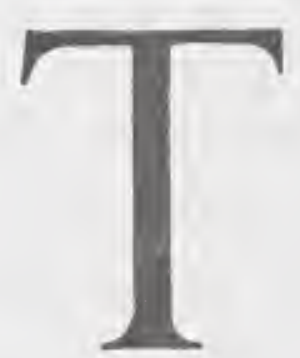

HE CHANGING HOURS OF SUNLIGHT are the key to rapid growth \& maturity. Midsummer's day in mid-America, June 21, is fifteen hours thirty-six minutes long. By August 1 it's shortened to fourteen hours forty minutes. September 1 has thirteen hours of light. The plants are totally locked into these cycles of changing light, \& a longer night is the hurry-up signal that forces them to mature.

Plants started outdoors in mid-June will mature almost simultaneously with earlier plantings. When the plant's day is long, longer than fourteen hours, no blooming can occur. The plant grows extremely rapidly, but only leaves appear. Only when the light level has dropped to days shorter than thirteen hours will blooming occur.

Plants grown indoors may be forced to bloom any time by manipulation of the hours of darkness. Indoor growers can make use of this trigger by subjecting plants to an eight-hour day for three to five days, \& withdrawing light completely the other sixteen hours. Then resume normal lighting. The plants will exhibit visible flowers about two weeks later. This is a perfect technique for small growers with limited space \& works best with plants at least six weeks old.

Large outdoor plantations can't physically accom- 
plish this, \& ideally should be located where a decent fall climate exists.

Pot is affected by light in other ways. After several years of observation, it appears to me that plants receiving the orange-red light of sunset mature sooner than those on the east side of the garden. Orienting the plants so they receive the sunset rays will shorten the growing period by as much as two weeks. Wide spacing outdoors helps.

If your growing site isn't very well lighted, raise the light level by using reflectors: white painted surfaces around the plants or just white paper pinned up or laid on the ground. In general, try to avoid street lighting or night lights that might shine on the plants; even low-level lighting could confuse flowering. Night should be night \& day day, as far as the plants are concerned. They are highly sensitive to small changes in environment \& respond visibly to changing conditions. As small an amount as .03 footcandles during the night can delay flowering indefinitely. *

\section{Frost}

The great limiter - baby plants can't stand any frost at all. Larger plants develop woody trunks that resist freezing. Blossoming females can survive repeated light frosts, but too much ruins the flavor \& blackens the leaves. Temperatures below 28 degrees will freeze the plant completely. Cover threatened plants with blankets, plastic, etc., or harvest them immediately.

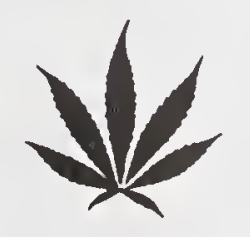

*"Photo Periodic Responses of Hemp", H.A. Borthwick \& N.J. Scully in the Botanical Gazette, 1954 


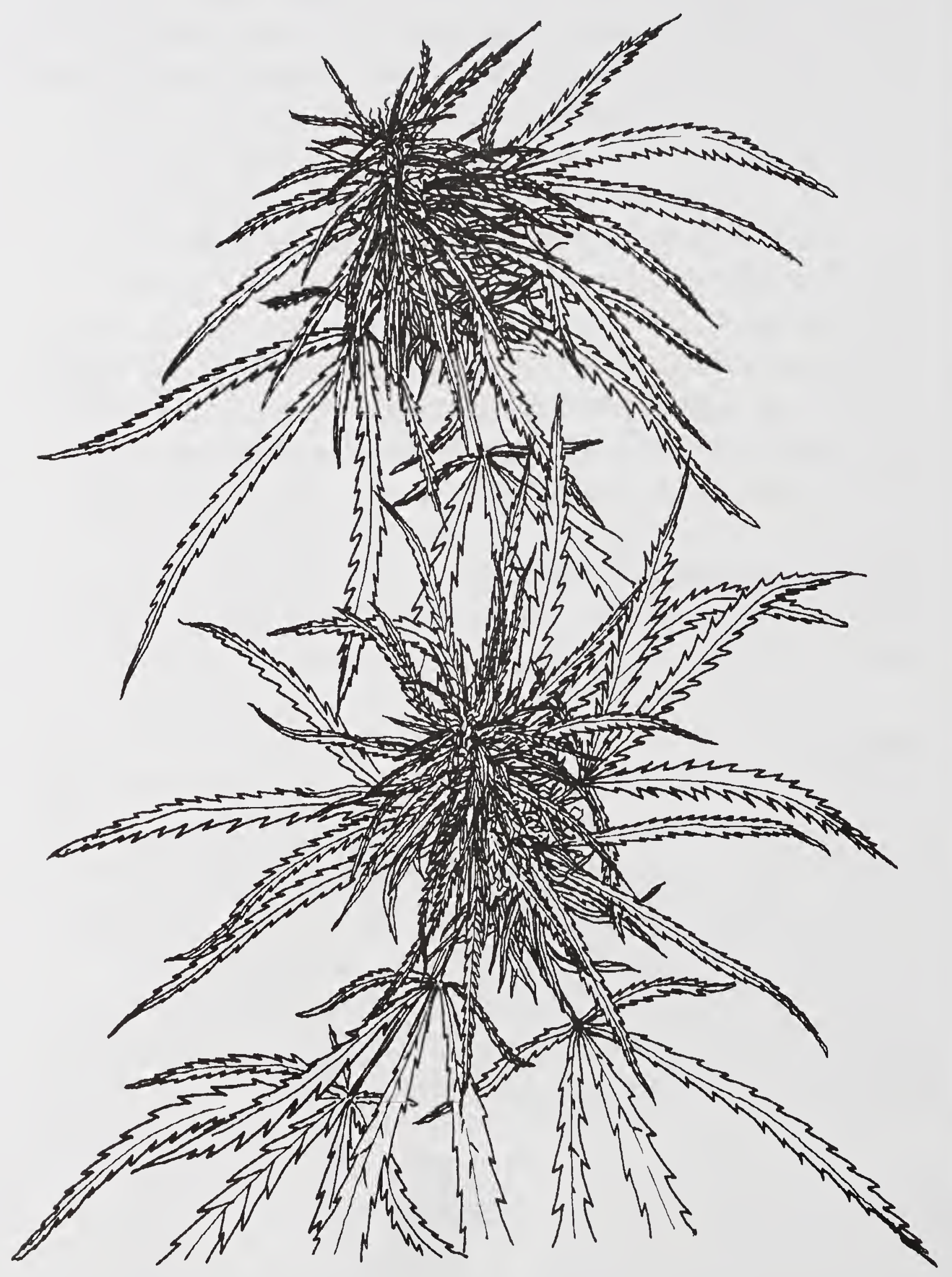




\section{Harvest Time}

\section{The Big Payoff}

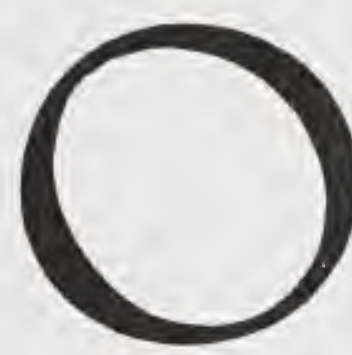

VER MOST OF North America the time of harvest is usually between the equinox, September 21, \& October 10. Some plants mature two to three weeks earlier or later.

When you think you have waited long enough, go out with the scissors \& snip off a few buds. Dry them quickly \& roll. The little flowers should stick to your fingers, smell wonderful, \& smoke very poorly (you will have to relight for every toke). The white feathery pistils should be turning brown or gold. Close examination of the flower tops should show sparkling droplets of resin all over the flowers \& small leaves.

When the flowers are ready to pick, half of the little feathers should have turned gold. The big leaves have started to hang down \& turn yellow. The leaves on the tops bend back, tips pointing down. The plant is preparing to die \& looks like it. Check for seeds: if the plants have lots of seeds, harvest before most of the seeds turn dark. If they have only a few seeds, wait until some, at least, are mature \& black enough to plant next year.

If you allow severe paranoia to control harvest, you lose. It is very hard to go on waiting a few more days, but that's what you must do. Grit your teeth \& sleep out there with the flashlight, borrow a barking dog, rig up some 
bells on invisible fishline, anything. Those last warm days of sunshine, the famous "Indian summer, " put a final spurt of energy into the flowers that's worth waiting for.

However, if rain is pouring down, fear not. Perfectly fine marijuana has been harvested from saturated fields. The rain does not injure the resin on the flowers nor does it ruin the flavor of the grass.

Watering should have been stopped a couple of weeks before the harvest since upward growth stops when the plant matures. A few plants may not be ready when the main crop is, so leave them in if possible. Remember, late bloomers should not be used for seed. Pick your best, earliest-blooming female to use for next year.

\section{Chop Chop}

Pick a warm sunny day if you can. Watch the weather report closely \& cut before it rains.

There are several ways to harvest:

The Nibble Method: Only for frost-free areas. The ends of the branches will mature sooner than the lower buds. Go out with the scissors every day for a few weeks \& trim off the best-looking stuff. Carefully cut only the flowers as this will cause new, smaller flowers to form in the same spot. Good for small plots, but very time-consuming.

The Clean Sweep: Cut the plants at ground level with a saw or knife.

Pulling Up By the Roots: Nearly impossible with compost-grown plants. Besides, it gets the dope all dirty, \& boiling the roots seems mean.

Immediately take the plant out of the sun. Drying in the sun destroys the fine green color \& sweet taste. Dry it slowly in a dark place at a cool room temperature with good air circulation. If you have a tall drying place, hang 
the whole plant upside down from a nail; or cut the plant into sections, removing the main stalk, \& hang the pieces. Hanging upside down makes a classy, neat finish to the dry tops, with all the leaves in order, nothing squished or bent. For more rapid drying, trim off all the tops \& discard the big leaves \& stems which contain a lot of water. Lay the tops on screens or hook them over strings strung across the room. The fresh wet stuff must be kept up in the air \& well separated, or it could get moldy.

A closet with the door slightly open or a basement is ideal. Put in an electric fan if it's humid or raining hard. Catalytic heaters work in areas without electricity.

Drying should take a week to ten days, leaving the plants dry but still a little springy. Don't let them get crumbly dry, or they will be impossible to handle. They will shrink a lot, even the monster tops. The results from slow drying are far superior to fast drying with heat. The slower it drys, the more flavor \& aroma the plant retains. 


\section{Storage}

7 HE BEST STORAGE CONTAINER is a glass jar with an airtight lid. Glass is totally moisture- \& vapor-proof \& will keep dope fresh a long time. Plastic ziplock bags are leaky \& worthless for long-term storage. Tins are fine if airtight, but no plastic lid is airtight. Keep the stash in a dark place; light will slowly reduce the amount of THC.

The very best place to keep your stash is in the freezer, if you have one. But do not freeze in plastic bags. Seeds survive freezing for years, especially if they are still in the flower. Refrigerators, however, are too damp \& get looked into too often, although an old refrigerator can be hidden away, turned up to its coldest, \& used just for the stash. Test it first to see if it will get cold enough, \& use a big old padlock.

Freshly dried tops, when packed into airtight glass jars \& frozen, will remain unchanged for at least a year. Which is all the time you need. 
Appendices

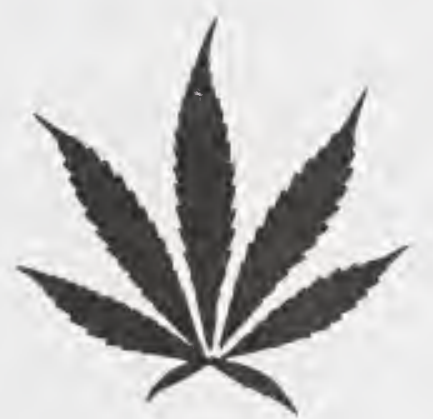




\section{How to Know When \\ A Plant Needs Your Help}

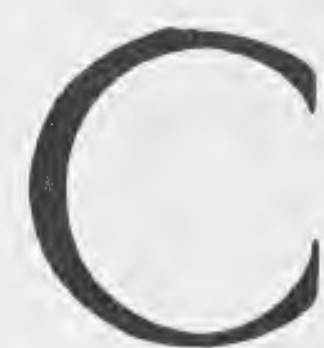

OLOR IS YOUR BEST INDICATION. A pale, yellowish or grayish plant is in need of aid. First check the soil. Soggy, watery soil or hardbaked soil needs aeration. Stick in the digging fork \& wiggle it all around the plant, mulch lightly with compost, \& water it well if dry.

Overacidity can also cause poor color. Check with $\mathrm{pH}$ paper. Correct with lime or ashes until the plant improves, dusting the soil before watering.

Check for gophers undermining the plants. An undermined plant needs extra water. Try to stuff topsoil or compost down the holes to fill them in. Step lightly around the base of the plant to reunite it with the earth. Water \& feed teas to the plant promptly \& regularly, as the roots have been damaged.

A general yellowing of all the older leaves may be a sign of nitrogen lack. Feed it fish emulsion or manure tea if it's young, but don't feed much nitrogen to a plant that's about to mature. A slight lack at maturity stimulates good flower production.

A creeping red tint under the leaves could be a phosphorus deficiency; work in a cup of bone meal or rock phosphate, then water it in.

Any other lack your plants might have due to poor 
soil can be helped with liquid seaweed fertilizer \& a heavy compost mulch.

Broken branches should be carefully propped up. When heavy weather arrives, blossoming plants can be knocked flat by the sudden weight of rain in flower clusters. Keep alert, there is nothing you can do but prop them up too. This can develop into quite a debacle, so forewarned is forearmed-tie them up.

During cold, wet weather, gray mold can appear on stems or in the flower clusters. Any mold-infested parts should be cut off immediately \& quickly burnt. This will halt the spread of the infection. This same mold can gallop through a stack of freshly-cut flower tops.

Insect damage to the hardy herb is usually minor, but occasionally you will have problems. 


\section{Pests $\mathcal{E}$ Diseases}

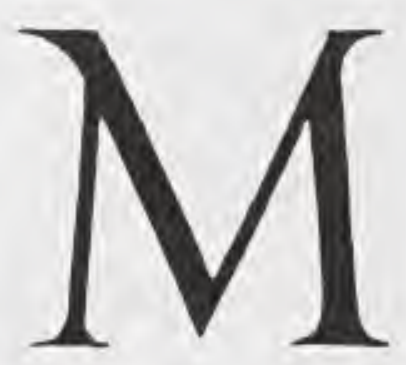

ARIJUANA GROWING IN THE NATURAL STATE is very hardy \& resistant to insect damage or plant diseases. Compost-grown plants outdoors are especially strong \& vigorous, only rarely needing doctoring. Greenhouse plants are far more vulnerable to insects \& illness because of their softness \& the artificiality of environment.

Plants growing indoors or in small pots will often look sick due to a lack of some basic essential, such as light, nutrients, or water.

When plants look sick or chewed up, the first thing to do is stop \& look at them very carefully.

Herbal lore calls for hemp as a companion plant for the cabbage family. The odor of the hemp confuses or repels the white cabbage butterflies that fill broccoli, cabbage and brussels sprouts with green caterpillars.

\section{Pests}

Snails \& Slugs: These can eat seedlings in one night, \& they will torment older plants by constant nibbling. Combat them by keeping the garden area cleaned up \& weeded. They hide during the day. Without shelter they will go away. Wood ashes sprinkled around the garden will slow them down. The best treatment is to pick them up \& get rid of them.

Aphids: Aphids are tiny, soft, sucking bugs, come in 
green or gray, \& are usually not a problem on marijuana. They can be gently rubbed off \& crushed, or washed off with water. Ladybugs will clean up any aphid attack.

Spider Mites: These are tiny reddish or black sucking insects, seen only in greenhouses or indoors, that fill the tops of the plants with delicate webs. The leaves develop whitish flecks on the topside, mottled silvery undersides. Hard to get rid of, spraying with soapy water, Nicotine Sulfate can help. Malathion is sometimes used and while it is registered for food crops, it is best to avoid if possible, it has a 15 day to harvest restriction, and is not organic.

White Flies: These are also greenhouse pests. Clouds of tiny whitish soft bugs fly off the leaves when you handle the plants. These greenhouse pests can be set back by a spray of very dilute fish emulsion ( 1 tablespoon per gallon). The plants love it, the bugs hate it.

Caterpillars, Weevils, Grubs, E Inchworms: Pick these things up \& crush them if you find them on your plants. They can be turned into fertilizer by drowning them in the compost-tea bucket.

Other Pests: Pack rats and ground squirrels will sometimes climb a plant \& cut off branches to stuff in their nests. Discourage them with wire net, stomping on the ground near their holes, dog shit near their front door, \&, as a last resort, cats or traps.

Rabbits E Deer: Also cows, horses, \& goats-all love to eat it sometimes, sometimes not. Young plants without fences around them will get eaten if these animals are common sights near your garden. Some garden stores sell deer repellent. Bunnies don't like blood meal sprinkled 
around. A good fence is best. A diversionary tactic is to interplant salad vegetables with the pot. Most munching animals vastly prefer cabbage \& lettuce to marijuana.

Two Legged Midnight Creepers: A simple detection system can be rigged for a small investment in wire, switches, \& a bell or buzzer. A battery-operated bell is triggered by trip wires (nylon fish line) attached to microactuators in the garden. A light that goes on when a switch is tripped is also a good addition.

\section{Babies Fall Flat}

Very young seedlings can "damp off" if allowed to get too dry \& are then overwatered for a few days. The tiny stem suddenly develops a thin spot \& the plant keels over on its side. This is caused by an organism living in wet soil. Marijuana seedlings will not "damp off" unless they have been weakened by drowning or serious thirst. There is no saving their lives. You must cut off the infected plants \& save the rest with extra care. Give plenty of strong sunlight, \& stop watering until the surface of the soil dries out. Make sure not to overwater afterwards. "Damp off" stops when the plants grow their third sets of leaves \& the stems harden. 


\section{Experimentation}

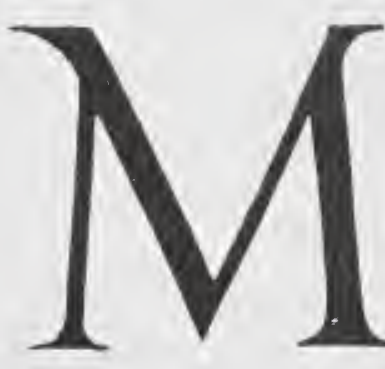

ARIJUANA FARMERS ALL OVER THE WORLD have secret treatments to produce their idea of perfection.

Thai farmers pray \& meditate in their gardens. One plant is recognized as the natural spiritual link \& is given special care \& attention. Sometimes an altar is built in the garden.

In Punjab, India, seed is planted in the mouth of a dead cobra.

In Mexico, plants are spiked through the base with cactus thorns, thought to stimulate the flow of resin.

Earth worshippers make love among the marijuana \& appeal to the great god Pan. The Ant Farm in northern California produced claims that THC can be recycled by planting in pots lined with your own shit.

There are lots of interesting ideas floating around about increasing the life energy of growing plants (not grass specifically). One is wrapping a spiral of copper foil strips around the stem, another is encircling the growing area with a copper coil attached to a D.C. source to produce a magnetic field. Some recommend constructing open-frame pyramids over the plants.

Another trick is to bury several magnets in the soil at the base of the plant at planting time, or to magnetize iron filings \& work them into the soil. 


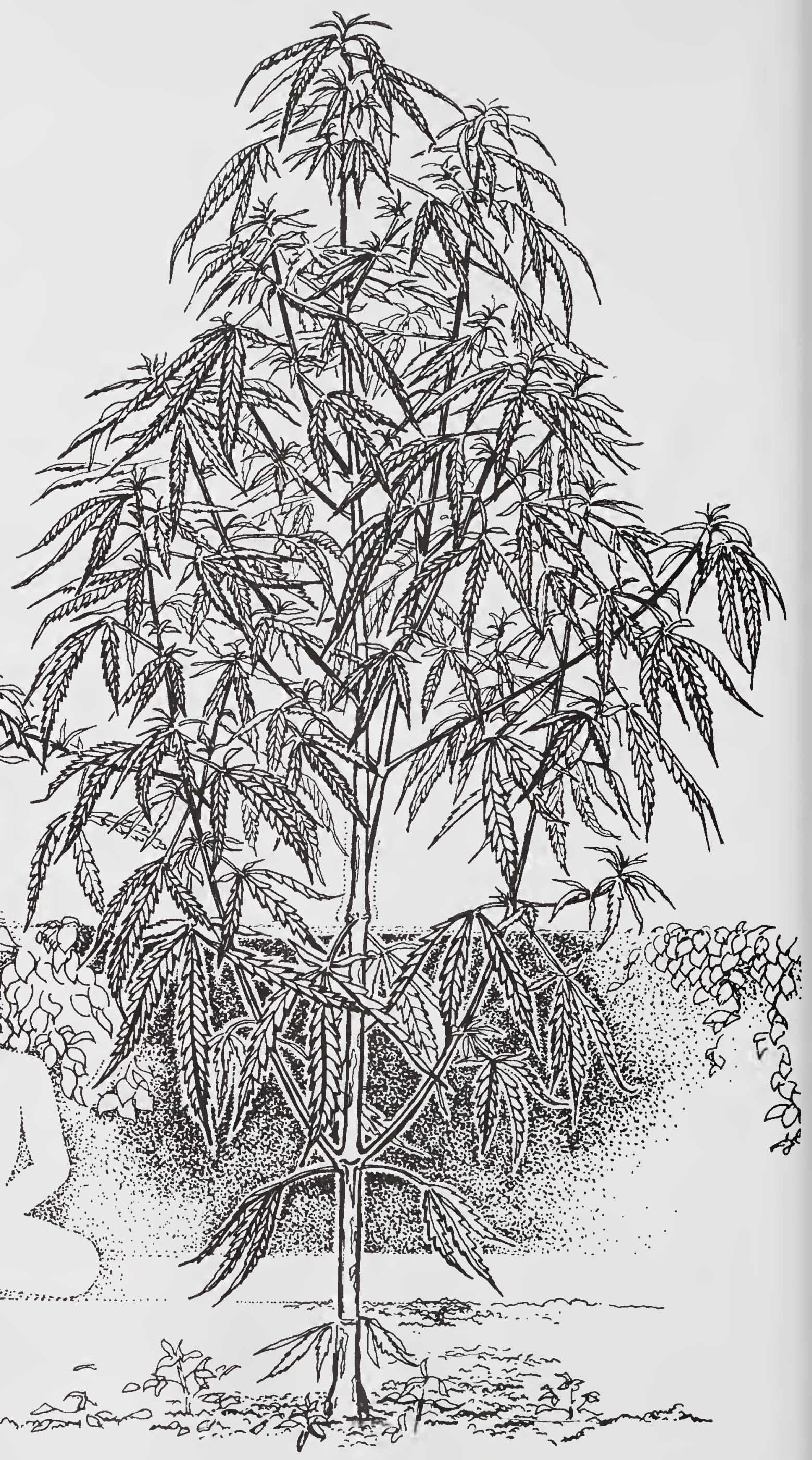


People have tried playing various types of music to plants. Heavy rock was a dud, but plants responded favorably to Ravi Shankar \& Hawaiian steel guitar.

An excellent source of vague but fascinating information about these \& other weird experiments is Peter Tompkins' The Secret Life of Plants, a lengthy compendium of off-beat gardening lore with a magnificent bibliography. Also, some very advanced thinking about composting has been published by Rudolf Steiner \& his school of Biodynamic farming, \& is well worth checking out. 


\section{Barney's Tequila Verde}

Pour gold label tequila out of its bottle, \& loosely pack it with green, dried buds of homegrown, seedless pot.

Pour the tequila back in.

Hide the bottle in the dark for three or four weeks. Give it a little shake now \& then.

Drink - watchout - before six weeks old. A strange buzz... the taste is incredible.

If you want to save it, drain the "green tequila" off into another container after five weeks of soaking. Throw away the marijuana, or eat it if you want.

Leaving the tequila \& the marijuana together for too long changes the flavor for the worse. 


\section{Marijuana Butter}

Use old stash, stems, big leaves, the moldy unsmokable. Simmer $1 / 4$ pound of mediocre grass or 1 pound of stems \& leaves in a large kettle of water \& stir often. After two hours add $11 / 2$ pounds of butter. Stir well.

Simmer for at least twelve hours, stirring occasionally. Add water as it gets low.

Remove from heat \& pour the liquid through a strainer into another container. Pour a little boiling water through the stems \& leaves \& squeeze them hard into the container.

Pour boiling water again \& repeat until all the butter is squeezed out. Throw away the marijuana debris.

Let the liquid cool until cold. All the butter will float to the top \& harden. Scoop off the butter, place it in a saucepan \& gently melt it. All debris will settle to the bottom of the pan. Slowly pour warm butter through a fine strainer into a bowl.

Chill \& use like regular butter in your favorite cookie recipe.

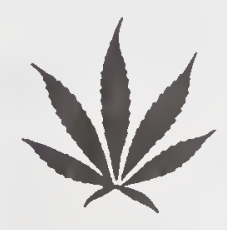




\section{Selected Bibliography}

Drake, William D. International Cultivator's Handbook. Berkeley: Wingbow Press, 1974. Cannabis as medicine in ancient uses.

Frank, Mel \& Rosenthal, Ed. Indoor Outdoor Marijuana Grower's Guide. San Francisco: And/Or Press, 1973. Two city boys grow it in closets. Complete instructions.

Frazier, Jack. The Marijuana Farmers: Hemp Cults and Cultures. New Orleans: Solar Age Press, 1974. Excellent background information.

Gottlieb, Adam. The Art and Science of Cooking with Cannabis. San Francisco: Level Press, 1974. All about eating grass. Very good book.

Growing Extraordinary Marijuana. San Francisco: Level Press, 1974. Very fine small book. Secrets from around the world.

The staff of "Organic Gardening and Farming," J.I. Rodale, editor-in-chief \& others. The Complete Book of Composting. Emmaus: Rodale Books, 1960. Mighty tome on all aspects, large \& small.

The Encyclopedia of Organic Gardening. Emmaus: Rodale Books, 1959. Excellent general garden information.

Panama Rose. The Hashish Cookbook. San Francisco: Level Press, 1974. Classic Moroccan recipes.

Tompkins, Peter \& Bird, Christopher. Secret Life of Plants. New York: Harper \& Row, 1973.

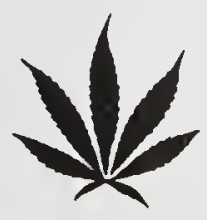


Planting Notes \& Log

Location Map:

Date:

Soil Type: 


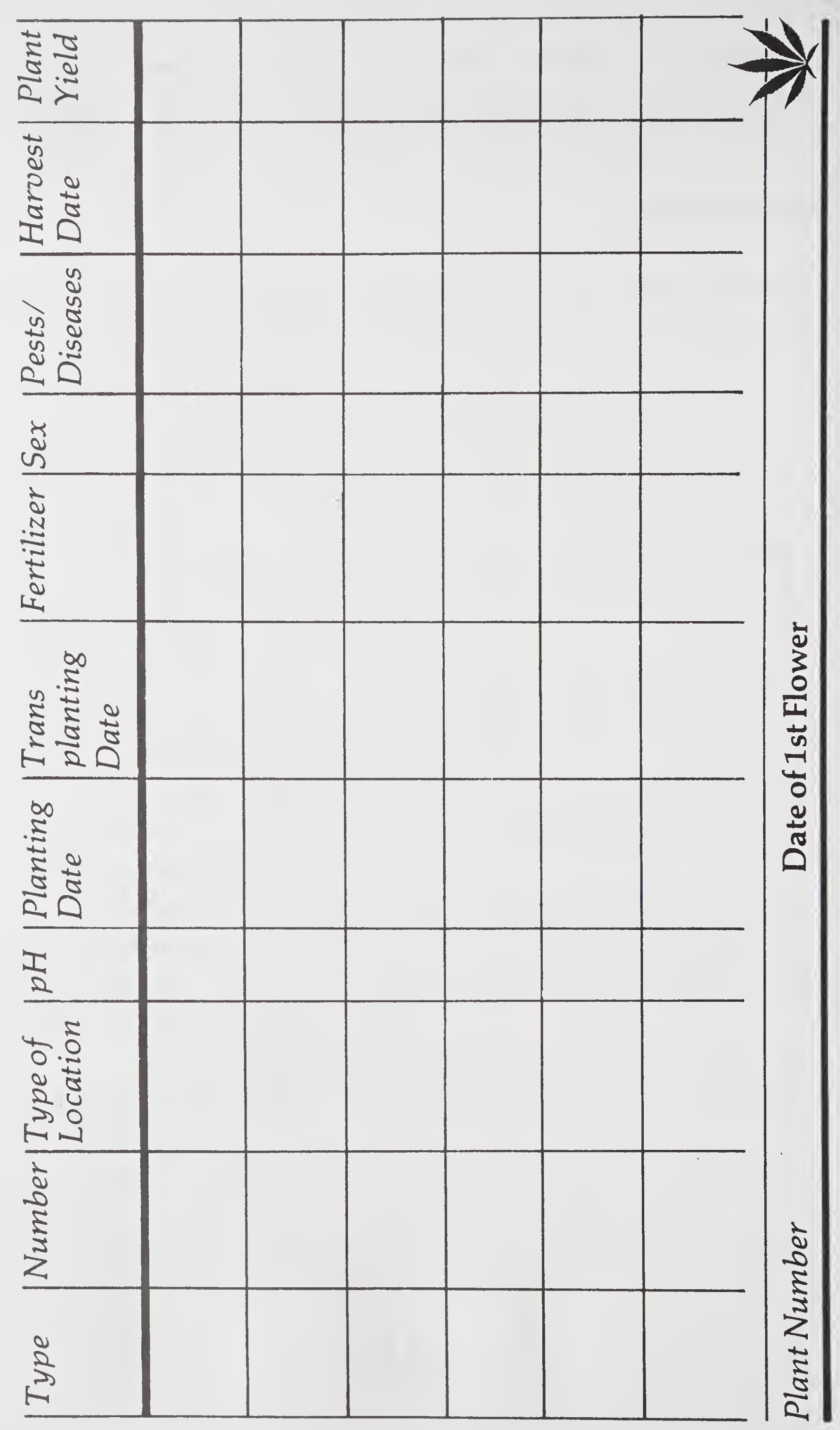


Planting Notes E Log

\section{Location Map:}

Date: 


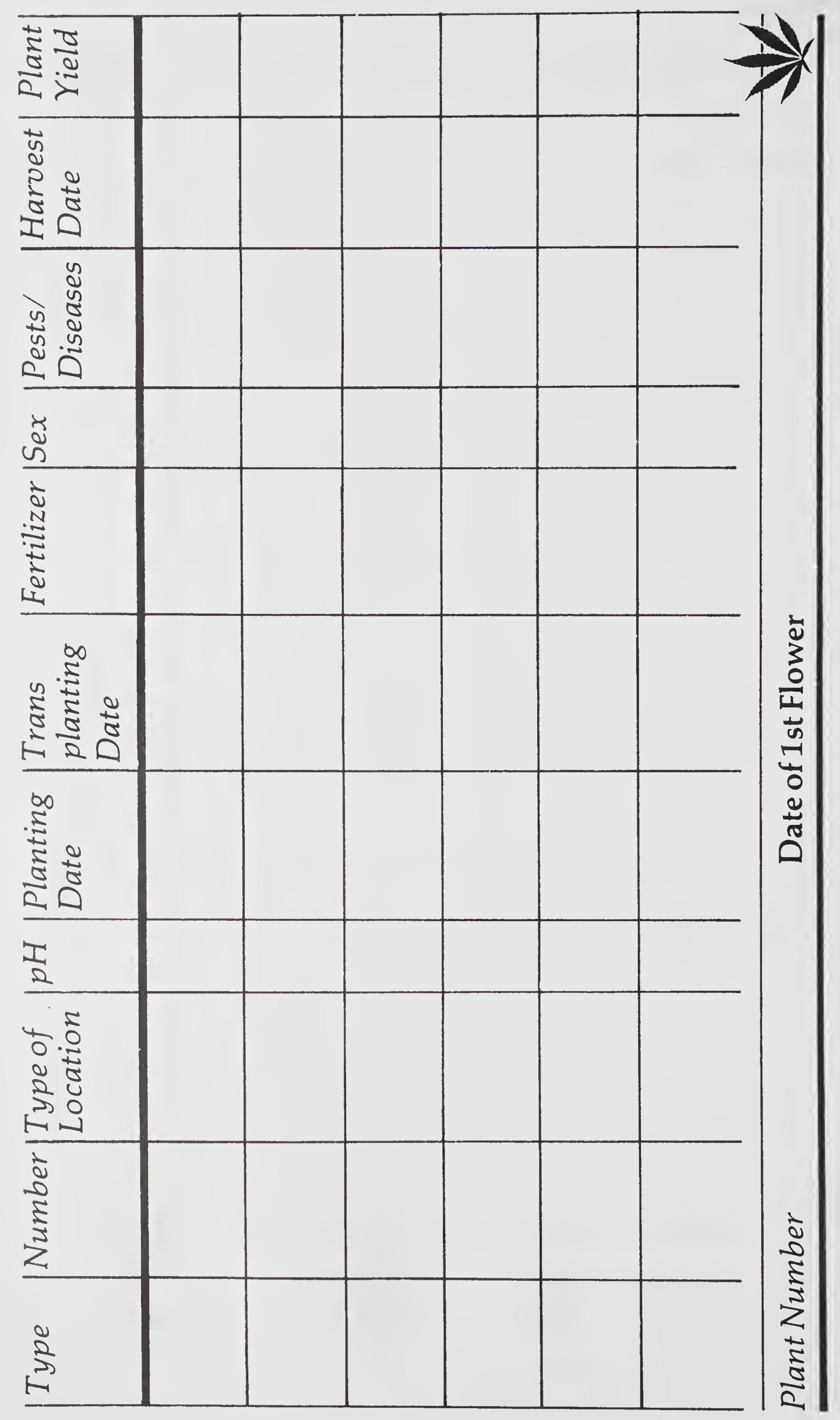




\section{Win All Your ARguments}

"No law should be more harmful than the behavior it seeks to regulate."

-Ed Rosenthal

UPDATED with the latest information on the government war on marijuana

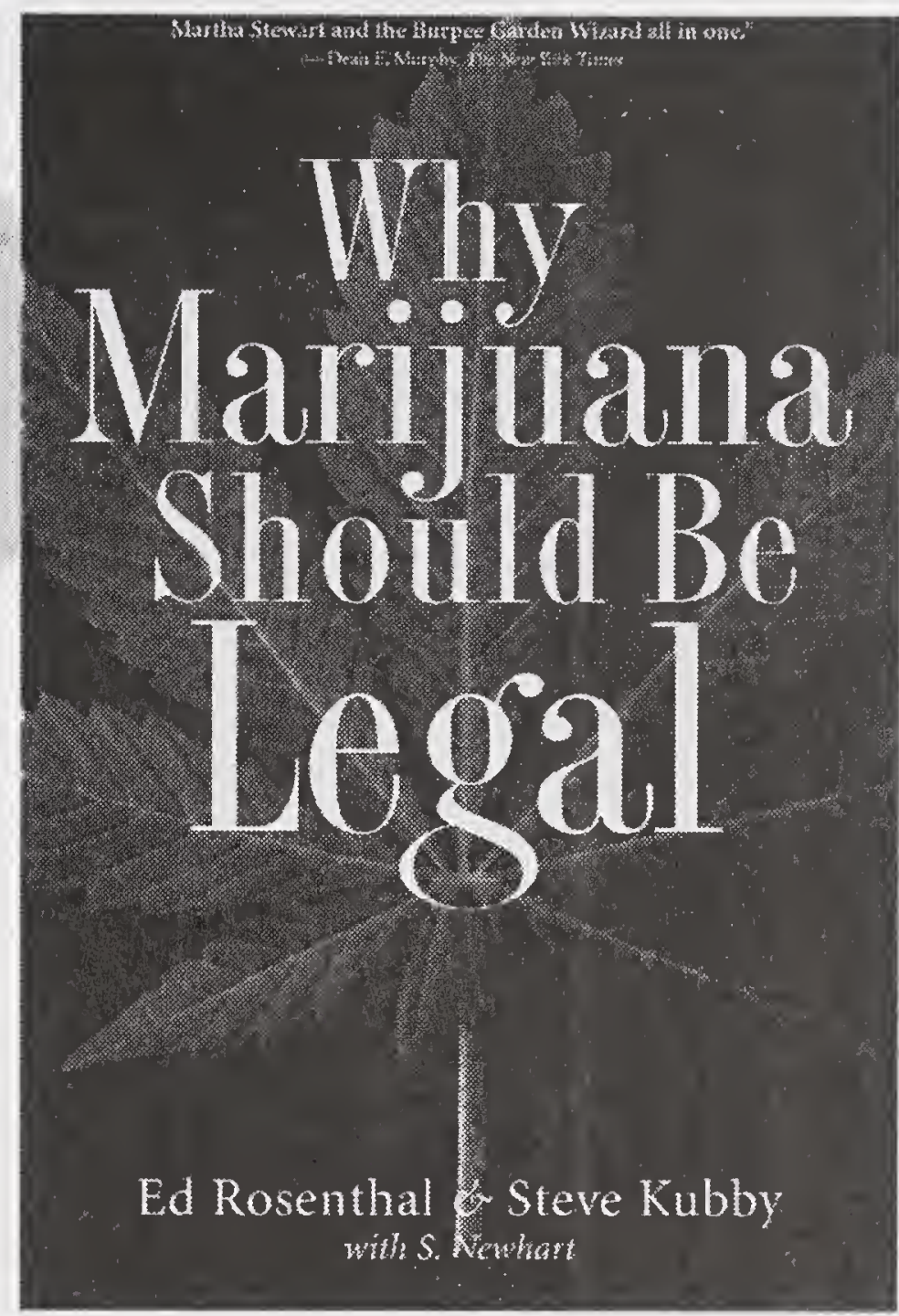

Why Marijuana should Be legal

by Ed Rosenthal and Steve Kubby

with S. Newhart

Learn what the arguments are for legalizing marijuana, based on the government's own facts and figures. Completely revised and updated with new charts and graphs illustrating the cost and injustice of the American war on marijuana. Why Marijuana Should Be Legal also includes a useful list of marijuana reform organizations. 


\section{Get Cold from Your trash}

\section{ASK ED \\ Marijuana Gold-Trash to Stash \\ by Ed Rosenthal}

Written with both the knowledge and easy-tounderstand style you expect from America's guru of ganja, Ask Ed: Marijuana Gold shows simple, safe recipes for:

EDIBIES - The best ways to prepare cannabis cuisine Tinctures - Hassle-free to make and inconspicuous to use Water HASH - Using ice and water, create hash from trim KIFF - THC glands are easily removed from vegetation VAPORIZERS - How they work, reviews of major models

Illustrations and photos clarify the step-by-step instructions. No other book gives you so many ways to maximize your harvest.

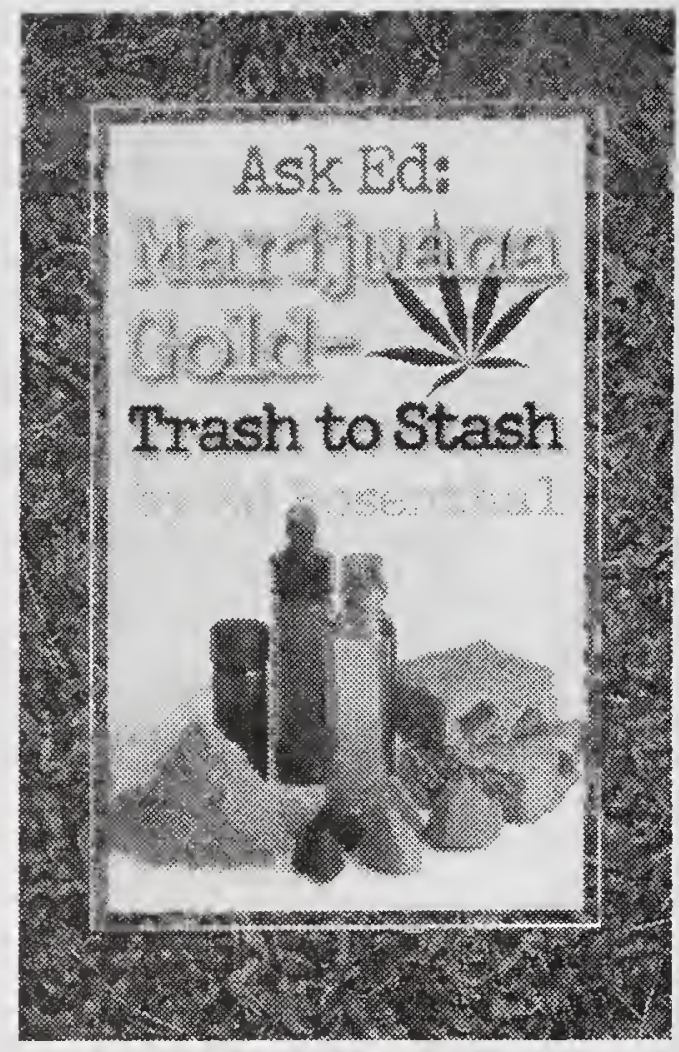

175 pages

Price: $\$ 14.95$

\section{REAL}

\section{GARDEN}

\section{SUCCESS INDOORS}

\section{Garden Tours and Tips}

by Ed Rosenthal

Join Ed Rosenthal for a unique tour of twelve indoor home gardening operations of real people, complete with easyto-follow how-to instructions for replicating these successful setups.

Go behind closed doors and peek into actual grow rooms to see how gardeners maximize space and lighting to increase quality and yield. Full-color photography of both soil and hydro gardens throughout this over-size, magazine-format book.

\section{REAL RESUHTS}

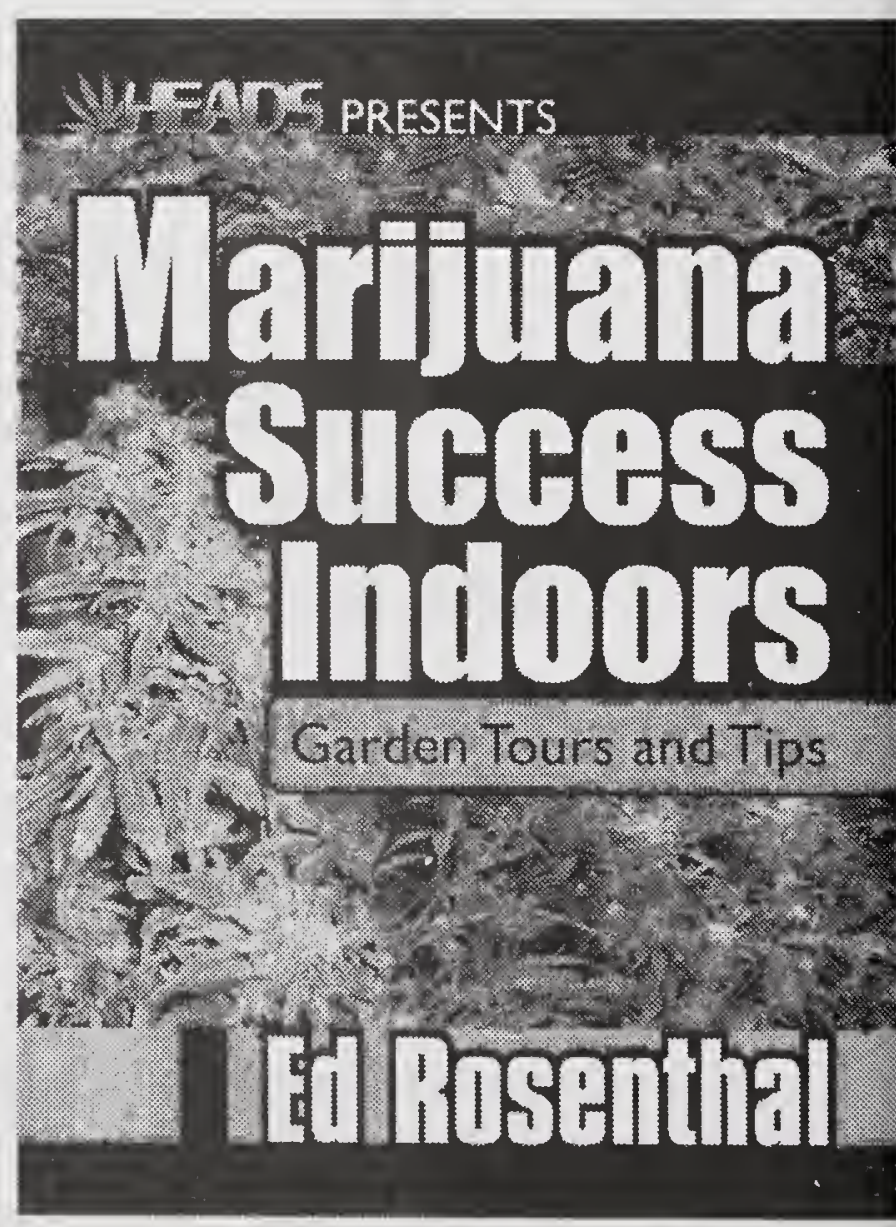

80 full-color pages

Price: $\$ 12.95$ 


\section{Ask Ed: \\ Marijuana Law \\ Don't Get Busted}

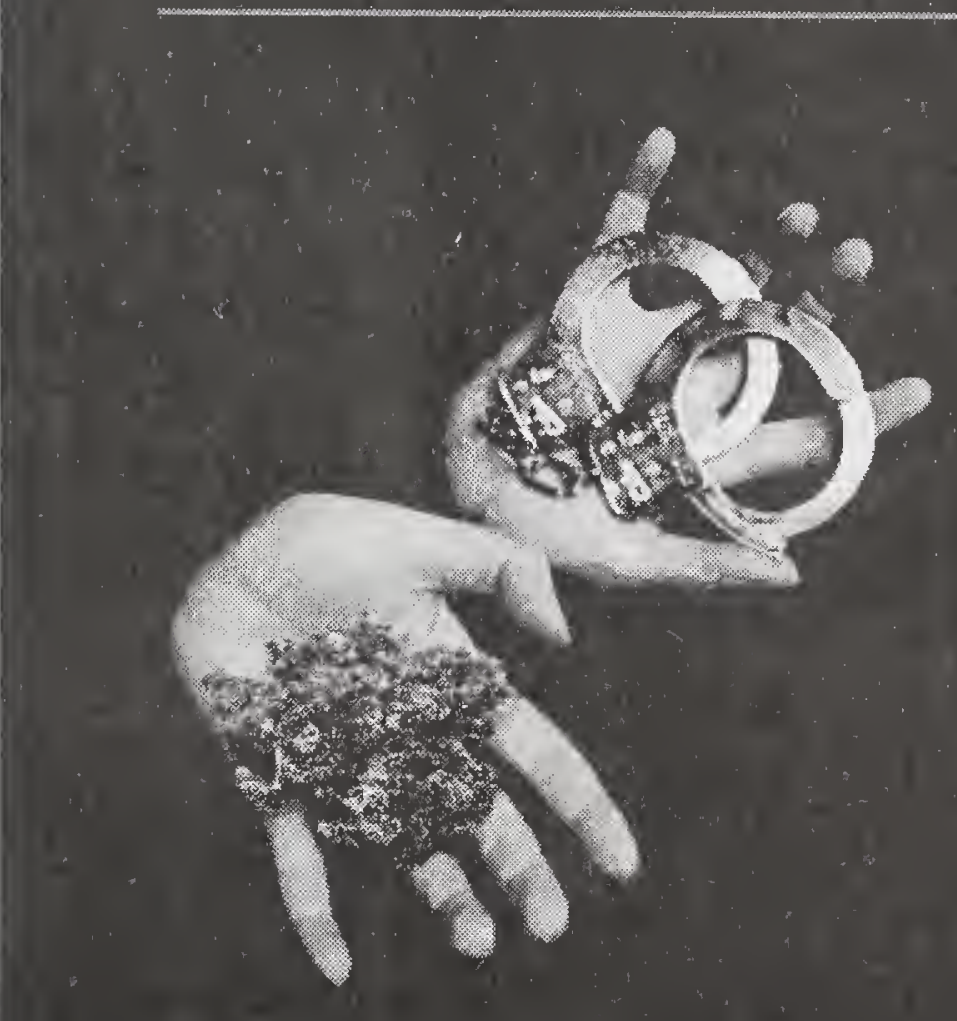

\section{Ed Rosanhal and Whllam Iogan Ary.}

\section{Ask Ed: Marijuana Law Don't Get Busted}

by Ed Rosenthal and William Logan, Atty.

Don't let an incident become an accident.

Next time you're in the wrong place at the wrong time, know your rights and don't get busted!

"...Rosenthal's book is a safety manual that will save the lives of people and plants." - Cannabis Culture Magazine Feb. 2001

"Being informed is one of the best ways to arm yourself in the on going war against marijuana users." - Ed Rosenthal 


\title{
WWw.quicktrading.com online home of Ask Ed ${ }^{\mathrm{TM}}$
}

\section{Grow Tips}

\author{
Politics
}

Links to the best cannabis sites

\author{
Buds
}

Marijuana Question:

Come online and Ask Ed 



\section{HOME GROWN IS THE BEST}

Primo Plant's casual, candid, easy-to-follow approach to growing marijuana sets it apart from other books.

Mountain Girl simplifies outdoor growing, using natural and organic techniques. She provides all the information needed to grow a continuous supply of marijuana. Best of all you don't have to have high tech equipment, or a botany degree, to make the most of this book.

"Primo Plant shows you how to use simple, reliable techniques to grow potent bud: It's the best outdoor book."

\section{Ed Rosenthal}

"So many of my friends were asking me how to grow marijuana I realized I had to write a book for everyone."

\section{Mountain Girl}

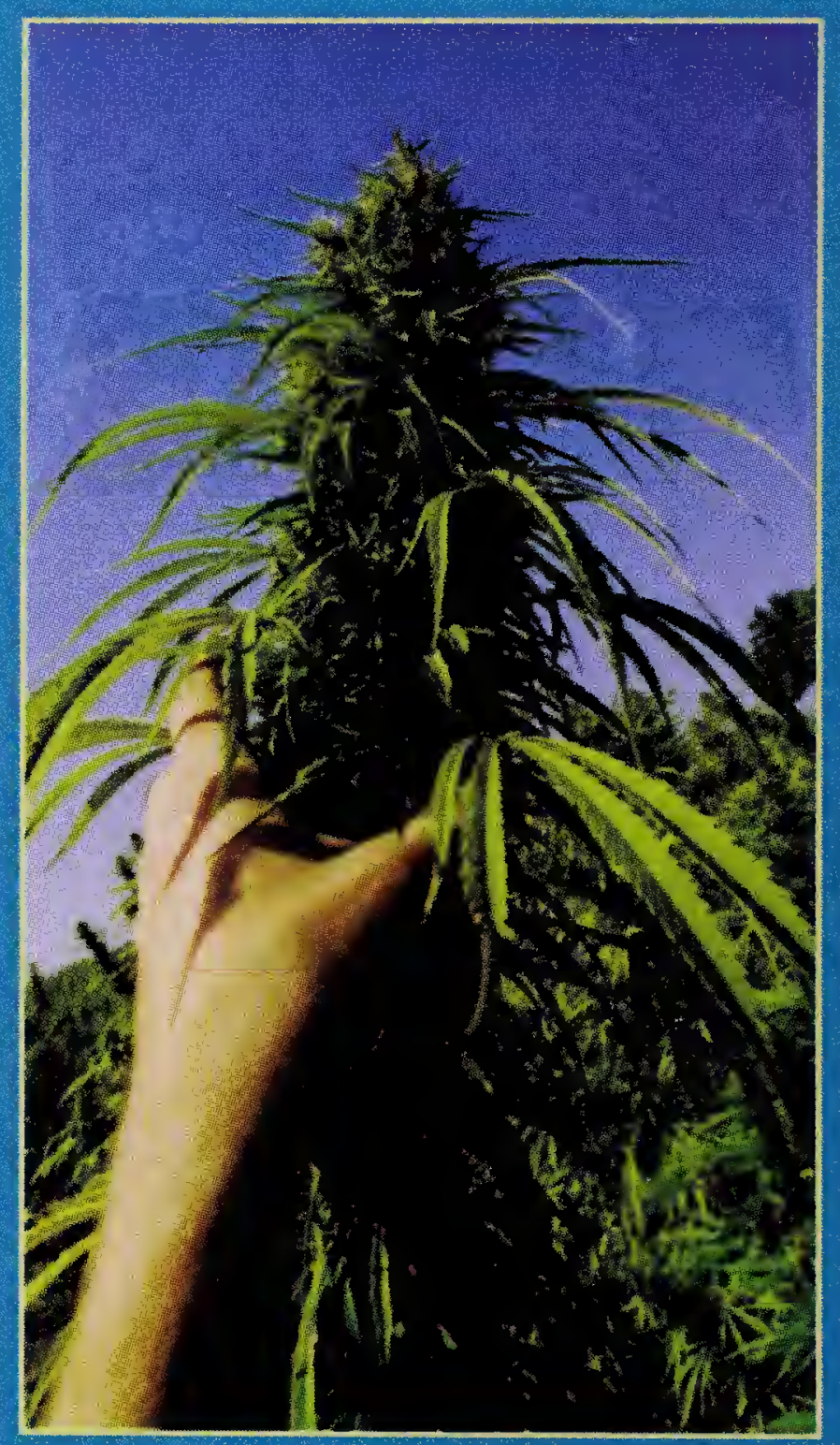

U.S.A. $\$ 14.95$

Canada $\$ 21.95$

U.K. 211.99

Quick American Archives www.quicktrading.com

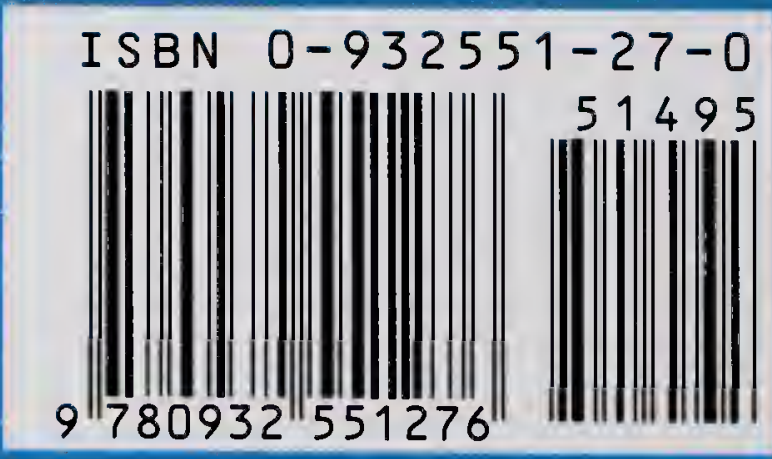

